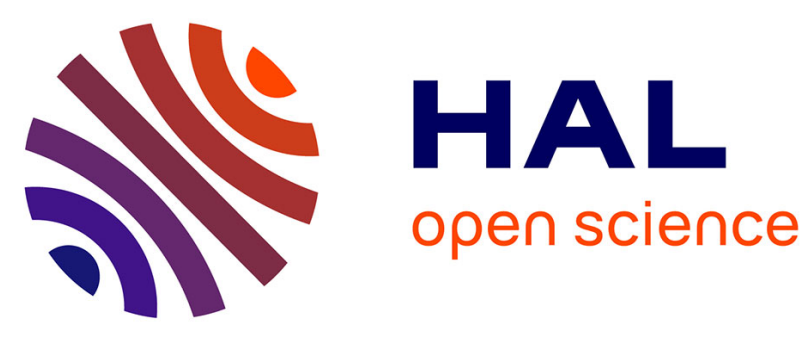

\title{
Design of functional electrospun scaffolds based on poly(glycerol sebacate) elastomer and poly(lactic acid) for cardiac tissue engineering
}

Florence Flaig, Hélène Ragot, Alexandre Simon, Gaëlle Revet, Maria Kitsara, Lisa Kitasato, Anne Hebraud, Onnik Agbulut, Guy Schlatter

\section{To cite this version:}

Florence Flaig, Hélène Ragot, Alexandre Simon, Gaëlle Revet, Maria Kitsara, et al.. Design of functional electrospun scaffolds based on poly(glycerol sebacate) elastomer and poly(lactic acid) for cardiac tissue engineering. ACS Biomaterials Science and Engineering, 2020, 6 (4), pp.2388-2400. 10.1021/acsbiomaterials.0c00243 . hal-02888775

\section{HAL Id: hal-02888775 \\ https: / hal.sorbonne-universite.fr/hal-02888775}

Submitted on 3 Jul 2020

HAL is a multi-disciplinary open access archive for the deposit and dissemination of scientific research documents, whether they are published or not. The documents may come from teaching and research institutions in France or abroad, or from public or private research centers.
L'archive ouverte pluridisciplinaire HAL, est destinée au dépôt et à la diffusion de documents scientifiques de niveau recherche, publiés ou non, émanant des établissements d'enseignement et de recherche français ou étrangers, des laboratoires publics ou privés. 
Design of functional electrospun scaffolds based on poly(glycerol sebacate) elastomer and poly(lactic acid) for cardiac tissue engineering

Florence Flaigg,1, Hélène Ragot ${ }^{\mathrm{b}, 1}$, Alexandre Simon $^{\mathrm{b}}$, Gaëlle Revet ${ }^{\mathrm{b}}$, Maria Kitsara ${ }^{\mathrm{b}}$, Lisa Kitasato $^{\mathrm{b}}$, Anne Hébraud ${ }^{\mathrm{a}}$, Onnik Agbulut ${ }^{\mathrm{b}, 2^{*}}$, Guy Schlatter ${ }^{\mathrm{a}, 2^{*}}$

a ICPEES, Institut de Chimie et Procédé pour l'Energie l'Environnement et la Santé, CNRS UMR 7515, ECPM-Université de Strasbourg, 25 rue Becquerel, 67087 Strasbourg Cedex 2, France ; florence.flaig@etu.unistra.fr; anne.hebraud@unistra.fr; guy.schlatter@unistra.fr

${ }^{\mathrm{b}}$ Sorbonne Université, Institut de Biologie Paris-Seine (IBPS), CNRS UMR 8256, INSERM ERL U1164, Biological Adaptation and Ageing, 75005, Paris, France; helene.ragot@inserm.fr; alexandre.simon@sorbonne-universite.fr; $\quad$ gaelle.revet@sorbonne-universite.fr; maria.kitsara@sorbonne-universite.fr; universite.fr

${ }^{1}$ These authors contributed equally.

${ }^{2}$ These authors jointly supervised this work.

* Corresponding authors: Prof. Guy Schlatter, guy.schlatter@unistra.fr ; Prof. Onnik Agbulut, onnik.agbulut@sorbonne-universite.fr 


\begin{abstract}
:
Many works focus on the use of polyesters like poly(lactic acid) (PLA) to produce nanofibrous scaffolds for cardiac tissue engineering. However, such scaffolds are hydrophobic and difficult to functionalize. Here, we show that adding 30\% of poly(glycerol sebacate) (PGS) elastomer within PLA leads to PLA:PGS scaffolds with improved biological properties, depending on the processing parameters. Two categories of fibers were produced by blend electrospinning, with diameters of 600 and $1300 \mathrm{~nm}$. The resulting fibers were cured at $90^{\circ} \mathrm{C}$ or $120^{\circ} \mathrm{C}$ in order to achieve two different crosslinking densities. The designed scaffolds were considered for cytocompatibility, biocompatibility, biodegradability, chemical and mechanical properties. Our results demonstrated that the presence of PGS increases the hydrophilicity of the material and thus improves surface functionalization by Matrigel and laminin coating, a commonly used cell culture matrix. PLA:PGS scaffolds associated with Matrigel and laminin allow an increased material-cell interaction. Moreover, the cardiomyocytes seeded on such scaffolds acquire a morphology similar to that observed in native tissue, this result being more remarkable on fibers having the smallest diameter and the highest PGS crosslinking density. In addition, these scaffolds induce neovascularization without inflammatory response and foreign body giant cell response after grafting on mice's heart. Hence, the improved biocompatibility and the ability to support cardiomyocytes development suggest that thin PLA:PGS scaffolds could be promising biomaterials for cardiac application.
\end{abstract}

Keywords: electrospinning; poly(glycerol sebacate); cardiomyocytes; cardiac tissue; epicardial graft 


\section{Introduction}

Cardiovascular diseases (CVD) are the leading cause of morbidity and mortality in industrialized countries and their incidence is constantly increasing due to the progressive ageing and rapidly expanding global population. ${ }^{1}$ In particular, myocardial infarctions (MI), which are induced by coronary artery occlusion, contribute to at least $\sim 20 \%$ of the reported deaths. $^{2}$ The poor regeneration capacity of adult cardiomyocytes limits the potential to restore cardiac function after MI resulting in heart failure (HF). Heart transplantation remains the only radical treatment for end-stage HF, but its indications are limited by organ shortage and by the complications associated with major immunosuppression. Therefore, other approaches facilitating cardiac repair after MI, like tissue engineering, are urgently needed.

Electrospinning is a process increasingly used in the field of tissue engineering. ${ }^{3-7}$ The use of electrospun scaffolds can enhance tissue regeneration thanks to their nanofibrous structure mimicking the extracellular matrix of native tissues. ${ }^{5,8,9}$ Synthetic biodegradable and biocompatible polyesters like poly( $\varepsilon$-caprolactone) (PCL) and poly(lactic acid) (PLA) are often used in electrospinning for tissue engineering. ${ }^{10-12}$ However, they are hydrophobic, biologically inert and difficult to functionalize. Moreover, they are too stiff for myocardial mat application, in which the scaffold has to allow for regular, synchronic cyclical stretch. ${ }^{13}$ In this context, the use of poly(glycerol sebacate) (PGS) could be promising. This biodegradable elastomer material has a Young's modulus matching heart's stiffness. ${ }^{14}$ It also shows a hydrophilic behavior, having a contact angle with water droplet of $42^{\circ} .{ }^{15}$ Finally, this biomaterial showed good biocompatibility in vitro as well as in vivo. ${ }^{16}$ Functionalization of PLA or PCL scaffolds with the addition of PGS is thus promising. However, PGS processing remains quite challenging because as a thermoset elastomer, it is insoluble and infusible. Thus, PGS-based materials are usually processed in two steps. In the first step, a soluble lowmolecular weight prepolymer (pPGS) is prepared by polycondensation of sebacic acid and glycerol. The resultant prepolymer can be dissolved or melted to be further electrospun. The 
last step is the crosslinking under heating of the prepolymer into the elastomer (PGS). However, pPGS cannot be directly electrospun ${ }^{17}$ because of its low molecular weight, resulting in the absence of entanglements. Thus, the association of polyester, as a carrier polymer, with pPGS for electrospinning could be a solution of choice. Tallawi et al. proposed the blending of PCL with pPGS to fabricate cardiac patches. ${ }^{18} \mathrm{C} 2 \mathrm{C} 12$ myoblasts and neonatal cardiomyocytes on PCL:PGS fibrous mats coated with fibronectin showed well-developed sarcomere structures and good cell-to-cell communication, depending on the fibers organization. However, in this work as in all using PCL, pPGS remains uncrosslinked because of the low melting point of PCL $\left(60^{\circ} \mathrm{C}\right)$, below PGS crosslinking temperature. Uncrosslinked pPGS in the scaffolds may cause some issues as it could be fast released. Moreover, such materials are difficult to sterilized, especially by autoclave. Polyvinyl alcohol (PVA), with a melting point higher than $160^{\circ} \mathrm{C}$, arises therefore as a better choice as carrier polymer. It was used by Jeffries et al. ${ }^{19}$ to make crosslinked PGS:PVA fibers that could be partially purified by dissolution of PVA in water. However, even though these fibers are not made of pure PGS, such materials may degrade at the same rate, which is too fast for cardiac applications. PLA, with a melting point of $150^{\circ} \mathrm{C}$, could thus be a good candidate. $\mathrm{Xu}$ et al. used PLA as shell material to make PGSbased membranes for cardiac engineering by coaxial electrospinning. ${ }^{20}$ They assume that PLA can here decrease the degradation rate of the scaffold. These membranes are able after annealing to support the beating activity of human embryonic stem cells-derived cardiomyocytes but in this system cardiomyocytes are in contact with PLA and not with PGS. Yan et al. ${ }^{15}$ fabricated PLA:PGS fibers by blend electrospinning. The presence of only $25 \%$ of PGS increases the hydrophilicity of the material and improves the mechanical properties. The authors showed that such membranes can improve neural cell adhesion and proliferation, illustrating how promising these materials are for nerve regeneration. Currently, no studies have been conducted on PLA-PGS fibers, prepared by blend electrospinning, for cardiac tissue engineering. 
In this work, we focus on PLA:PGS scaffolds prepared by blend electrospinning for cardiac tissue regeneration: the effects of the fiber diameter, the presence of PGS and its crosslinking density on the physico-chemical as well as the biological properties were evaluated. For this purpose, PLA was blended with pPGS and electrospun using various parameters in order to fabricate PLA:pPGS continuous fibers with $30 \%$ of pPGS. Two categories of fibers were produced, with diameters of 600 and $1300 \mathrm{~nm}$. The resulting fibers were cured at $90^{\circ} \mathrm{C}$ or $120^{\circ} \mathrm{C}$ in order to achieve two different crosslinking densities. The design of a scaffold must consider a number of requirements that involve cytocompatibility, biocompatibility, biodegradability, chemical and mechanical properties. ${ }^{7,21}$ Here, the presence of PGS not only allows elastomeric properties at the surface of the fibers, but its hydrophilic surface and the presence of $-\mathrm{OH}$ groups can favor the surface functionalization. To increase the cellular attachment, the surface of the fibers was also functionalized by Matrigel or laminin. The effect of fiber diameter, crosslinking condition and surface functionalization on the physico-chemical and mechanical behavior of the scaffolds was investigated. Then, to evaluate the cytocompatibility of the different scaffolds, neonatal rat cardiomyocytes were seeded on nude or matrigel-coated mats. Furthermore, the in vivo biocompatibility of the PLA:PGS scaffolds was studied in a cardiac environment, after implantation of acellular mats on the surface of the heart of healthy Swiss mice. Vascularization and low inflammation provide arguments for a potential cardiac application.

\section{Materials and Methods}

\subsection{Materials}

Poly(glycerol sebacate) prepolymer $(\mathrm{pPGS}$, degree of esterification $=85 \%$ ) was synthesized from a glycerol:sebacic acid (G:SA) molar ratio of 1:1 as described in the supporting information (see Figure S1) and used in the three following weeks. Poly(D-lactic acid) (PLA, 
Ingeo 7000D, NatureWorks), dimethylformamide (DMF, $>99.8 \%$, Sigma-Aldrich) and dichloromethane (DCM, >99.8\%, Carlo Erba) were used as received.

\subsection{Preparation of PLA and PLA:PGS fibrous mats}

PLA pellets were dissolved in DCM while pPGS was dissolved in DMF. Both solutions were stirred with a magnetic stirrer overnight and mixed together at least one hour before electrospinning. They were prepared and blended together in order to reach the desired PLA:pPGS and solvent ratios. To investigate the influence of the fibers diameter, solutions with $7 \mathrm{wt} \%$ of PLA and $3 \mathrm{wt} \%$ of pPGS in different solvent were prepared. DCM:DMF 6:4 (wt:wt) was used to make thin fibers and DCM:DMF 7:3 (wt:wt) for thick fibers. To investigate the influence of the presence or absence of PGS, solutions with $10 \mathrm{wt} \%$ of PLA in DCM:DMF 6:4 (wt:wt) were also prepared.

Electrospinning was performed using a home-made vertical set-up with two metallic 18-gauge needles and a cylindrical collector $16 \mathrm{~cm}$ away from the tip of the needles. Homogeneity of the mat was improved by rotation of the collector at $125 \mathrm{rpm}$ and translation of the needles. The needles and the collector were connected to high-voltage power supplies (SL10, Spellman). For each membrane, the corresponding solution was introduced in two different $10 \mathrm{~mL}$ plastic syringes. The solutions were injected to the tip of the needles at a constant rate by a syringe pump (Fisher Scientific) through silicone pipes. The fibers were collected on an aluminum foil at $22^{\circ} \mathrm{C}$ with a dew point between 7 and $8^{\circ} \mathrm{C}$ (relative humidity between 38 and $41 \%$ ). The experiments were performed during the time necessary to inject overall $5 \mathrm{~mL}$ of solution in accordance with the flow rate.

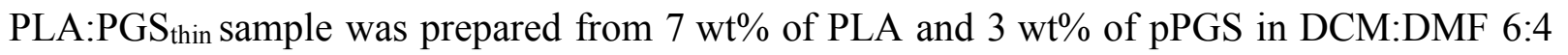
solution injected at $2.5 \mathrm{~mL} / \mathrm{h}$ at each needle with $18 \mathrm{kV}$ applied at the needles and $-2 \mathrm{kV}$ at the collector. PLA:PGS thick was prepared from $7 \mathrm{wt} \%$ of PLA and $3 \mathrm{wt} \%$ of pPGS in DCM:DMF 
$7: 3$ solution injected at $4 \mathrm{~mL} / \mathrm{h}$ at each needle with $18 \mathrm{kV}$ applied at the needles and $-2 \mathrm{kV}$ at the collector. PLA $A_{\text {thin }}$ was prepared from $10 \mathrm{wt} \%$ of PLA in DCM:DMF 6:4 solution injected at $2.8 \mathrm{~mL} / \mathrm{h}$ at each needle with $16 \mathrm{kV}$ applied at the needles and $-5 \mathrm{kV}$ at the collector.

The mats were peeled off from the aluminum, cut in the desired shape and fixed between two Teflon frames tighted together by screws in order to limit membrane shrinkage during curing. They were put in the vacuum oven (Vacutherm VT6025, Fisher Scientific) at room temperature with a pressure bellow $10^{-2}$ mbar during 30 minutes to let all the volatile compounds to evaporate. They were then heated at the desired temperature $\left(90^{\circ} \mathrm{C}\right.$ or $\left.120^{\circ} \mathrm{C}\right)$ for $48 \mathrm{~h}$ to achieve the crosslinking process of the pPGS into the elastomeric PGS. The crosslinked membranes were then kept in a desiccator before use.

\subsection{Physico-chemical and mechanical characterization of PLA and PLA:PGS mats}

The surface of the membranes was characterized by scanning electron microscopy (SEM) before and after the curing process. Prior to observation, the surfaces were coated by a thin layer of gold with a sputter coater (Q150RS, Quorum). The SEM (Vega 3, Tescan) was used in high vacuum mode with a voltage of $5 \mathrm{kV}$. The mean diameter of the fibers was calculated over 100 diameters measurements on each surface using ImageJ software (National Institutes of Health $[\mathrm{NIH}]$, Bethesda, MD, USA). Images after sterilization and after Matrigel coating were also taken to characterize potential surface modifications.

Differential Scanning Calorimetry (DSC) analyses were made to characterize the influence of formulation, curing or sterilization on the crystallinity of PLA in the fibers. Samples of approximately $2 \mathrm{mg}$ were introduced in the calorimeter (Q200, TA Instruments), heated and at $3^{\circ} \mathrm{C} / \mathrm{min}$ under a nitrogen atmosphere between $-20^{\circ} \mathrm{C}$ and $180^{\circ} \mathrm{C}$. The melting point $\left(\mathrm{T}_{\mathrm{m}}\right)$ and crystallization temperature $\left(\mathrm{T}_{\mathrm{c}}\right)$ were defined as the temperature at the maximum of the peak, 
respectively endothermic and exothermic. These temperatures, the corresponding enthalpies and the glass transition temperature were calculated with the software TA Universal Analysis.

Uniaxial tensile tests were performed on hydrated membranes to study the influence of formulation and curing on the mechanical properties. The samples were cut in a rectangular shape of $5 \mathrm{~mm}$ width and about $20 \mathrm{~mm}$ long. They were immersed in deionized water $24 \mathrm{~h}$ before measurement. Their thickness was then measured using a rheometer (Discovery HR-3, TA Instruments) with a compression procedure between Peltier plates at $0.5 \mu \mathrm{m} / \mathrm{s}$ : the thickness was evaluated as the gap between the plates when the variation of the axial force was higher than $0.05 \mathrm{~N} / \mu \mathrm{m}$. The same rheometer (Discovery HR 3, TA Intruments) was used with the Linear Tension Geometry. The specimens were fixed in the clamps with an initial gap of $10 \mathrm{~mm}$ and rehydrated before the beginning of the test. The tests were conducted at $100 \mu \mathrm{m} / \mathrm{s}$ until breaking. Five measurements were performed for each type of samples. Young's modulus (E) was calculated as the slope of the stress-strain curve in the initial linear region, and the Ultimate Tensile Strength (UTS) and the strain at break ( $\left.\varepsilon_{\text {break }}\right)$ were read on the curves.

The hydrophilicity of the membranes was characterized by the sessile drop method. The apparent water contact angle (WCA) was measured using a goniometer (DSA25, Krüss). The volume of the deposited droplet was $4 \mu \mathrm{L}$, and the mean angle was calculated from 10 droplet deposition for the most hydrophobic samples which did not absorb the water droplet. These values are given with the standard error of the mean. For more hydrophilic samples which absorbed water, the evolution of the apparent contact angle was recorded upon time.

\subsection{Isolation of neonatal cardiomyocytes and cell culture}

Newborn rat cardiomyocytes were obtained from 1-day-old Wistar RjHan rat (Janvier Labs, Le Genest-Saint-Isle, France). Once the ventricles were isolated, the cardiomyocytes were isolated using a neonatal heart dissociation kit (Miltenyi Biotec, Paris, France) according to the 
manufacturer's instructions. Before the seeding, all PLA and PLA:PGS mats were sterilized by autoclave $\left(121^{\circ} \mathrm{C}, 1 \mathrm{bar}, 15 \mathrm{~min}\right)$. Subsequently, to increase the cellular attachment, mats were functionalized through pre-incubation with a Matrigel solution (Corning Life Sciences, Amsterdam, The Netherlands) diluted in DMEM/F12 (Thermo Fisher Scientific, SaintHerblain, France) medium for $2 \mathrm{~h}$ at room temperature, and washed twice with phosphatebuffered saline (PBS) and then with culture medium. 8 × $10^{5}$ cells were seeded on the PLA and PLA:PGS mats maintained with a CellCrown ${ }^{\mathrm{TM}}$ (Scaffdex, Tampere, Finland) in a 48-well plate, and cultured with DMEM medium (with 4.5g/L D-Glucose and without Na Pyruvate) supplemented with L-glutamine, penicillin-streptomycin, 10\% horse serum and 5\% fetal bovine serum (FBS) at $37^{\circ} \mathrm{C}$ and $5 \% \mathrm{CO} 2$ for 3 or 6 days.

\subsection{Immunostaining and scanning electron microscopy (SEM)}

Immunostaining was used to assess cell morphology of cardiomyocytes on PLA and PLA:PGS mats. Briefly, samples were fixed in 4\% paraformaldehyde (PFA) for $10 \mathrm{~min}$ at room temperature (RT). Cells were permeabilized with $0.2 \%$ Tween (Sigma-Aldrich, France) and treated with $5 \%$ bovine serum albumin (BSA) blocking solution for $1 \mathrm{hr}$ at RT. Mouse anti- $\alpha$ Actinin (clone EA-53, 1:200, Sigma-Aldrich, France), mouse anti-vinculin (clone hVIN-1, 1:200, Sigma-Aldrich, France) and Alexa Fluor-488 goat-anti-mouse (1:1000, Thermo-Fisher Scientific, France) secondary antibodies were incubated for $1 \mathrm{~h} 30$ and $45 \mathrm{~min}$ at RT, respectively. Slides were mounted with mowiol containing $5 \mu \mathrm{g} / \mathrm{ml}$ Hoescht 33342 (Thermo Fisher Scientific, Saint-Herblain, France). Images were captured using a motorized confocal laser scanning microscope (Leica TCS SP5). All the measurements were performed blinded for experimental conditions using ImageJ software (National Institutes of Health [NIH], Bethesda, MD, USA). 
For the SEM observation, cells were fixed in $2 \%$ glutaraldehyde in phosphate buffer $(0.1 \mathrm{M})$ for $30 \mathrm{~min}$ at RT and washed again in the phosphate buffer. Then a post-fixation step took place using $1 \%$ osmium in sodium cacodylate $(0.1 \mathrm{M})$ for 15 min at RT. After, cell dehydration was performed in a series of increasing ethanol concentrations (50, 70, 95 and 100\%) for 10 min each. Finally, the samples were dried using critical point dryer for 2.5 hours. The samples were sputtered with a thin platinum layer prior to SEM observation using the (ACE600, Leica), and then analyzed using the Gemini SEM 500, from Zeiss. The images were performed by applying beam voltage of $1 \mathrm{kV}$ and using the SE2 detector.

\subsection{Cardiac surgery}

Fifty-four Swiss mice were used for the in vivo assessment. All procedures were performed in accordance with national and European legislations, in conformity with the Public Health Service Policy on Human Care and Use of Laboratory Animals under the license A751320. All animal studies were approved by our institutional Ethics Committee "Charles Darwin" (Permit number: 4370) and conducted according to the French and European laws, directives, and regulations on animal care (European Commission Directive 86/609/EEC). All animals underwent a left lateral thoracotomy after intraperitoneal ketamine $(100 \mathrm{mg} / \mathrm{kg}$; Merial, France)-xylazin (10 mg/kg; Bayer, France) anesthesia and tracheal ventilation. Analgesia was performed for 2 days after surgery with a $2 \mathrm{mg} / \mathrm{kg}$ intraperitoneal injection of profenid® (Merial). Acellular PLA and PLA:PGS mats were sutured (surface approximately $100 \mathrm{~mm} 2$ ) on the surface of the ventricle of the mice. The animals were sacrificed 7 and 28 days after implantation to assess the biocompatibility of PLA and PLA:PGS mats by cervical dislocation. After sacrifice, hearts were removed and weighted.

\subsection{Tissue processing, histological and immunohistochemical assessment}


For histological and molecular analysis, ventricles were separated in two halves by a short-axis section through the mid-portion of the heart. Upper part was immediately fixed in $4 \%$ of formaldehyde for $24 \mathrm{~h}$, dehydrated, and embedded in paraffin and lower part were snap frozen in liquid nitrogen immediately after dissection. Ten $\mu \mathrm{m}$ heart sections were made using a microtome (Leica Microsystems, Nanterre, France), stained with hematoxylin and eosin for visualization of general morphology and Sirius red for visualization of fibrosis, mounted in Eukitt (CML, France) and examined by light microscopy. Images were taken with a microscope (Leica Microsystems, Nanterre, France) equipped with a digital camera. At least five animals were used for each experimental point. In addition, immunolabelling was performed with antibodies directed against Caveolin-1 $\alpha$ (rabbit IgG, dilution 1:150, Santa Cruz Biotechnologies). Binding of primary antibodies was detected by incubating the sections with Alexa Fluor-conjugated anti-rabbit IgG (1:1000, Thermo-Fisher Scientific, France) secondary antibody. Slides were mounted with mowiol containing $5 \mu \mathrm{g} / \mathrm{ml}$ Hoescht 33342 (Thermo Fisher Scientific, Saint-Herblain, France). Images were captured using a motorized confocal laser scanning microscope (Leica TCS SP5).

\subsection{Statistical Analysis}

Analyses were performed using the Prism 6 software. Normality was check using ShapiroWilk normality test and equal variance was checked with the test of Bartlett. If normality of distributions and/or equal variance were not assumed, the non-parametric Kruskal-Wallis test was used instead of ANOVA. If a significant difference was found, then multiple comparison tests were performed to compare the different groups analyzed (Dunn's or Bonferroni's multiple comparison test following Kruskal-Wallis or ANOVA, respectively). The level of significance was set to 0.05 . Values are given as means \pm standard error of the mean. 


\section{Results}

\subsection{Control of the fibers morphology of PLA and PLA:PGS mats}

Here, the fibrous scaffolds were prepared by blend electrospinning followed by a crosslinking step (Figure 1). Solutions containing $30 \%$ of pPGS were used because preliminary experiments showed that higher percentages of pPGS reduce process stability and give less regular fibers. In the present work, different fibers diameters and annealing parameters are compared. Three different PLA or PLA:PGS solutions were electrospun giving three kinds of fibers. PLA $A_{\text {thin }}$ and PLA:PGS thin were prepared in DCM:DMF 6:4 and led to the fabrication of scaffolds with fiber diameter in the range of $600 \mathrm{~nm}$ whereas PLA:PGS thick were prepared in DCM:DMF 7:3 resulting in thicker fibers with average diameter in the order of $1100 \mathrm{~nm}$ (see Figure 2 and diameter distributions given in Supporting Information S3). While PLA and PLA:pPGS fibers prepared in DCM:DMF 6:4 have comparable diameters, fibers prepared in DCM:DMF 7:3 are significantly thicker because of the higher volatility of the solvent used for the latter. Indeed, as DCM has a higher vapor pressure than DMF, the DCM:DMF 7:3 solvent mixture evaporates faster during electrospinning than the DCM:DMF 6:4, giving less time to the electrospun jet to be stretched before getting dry. 


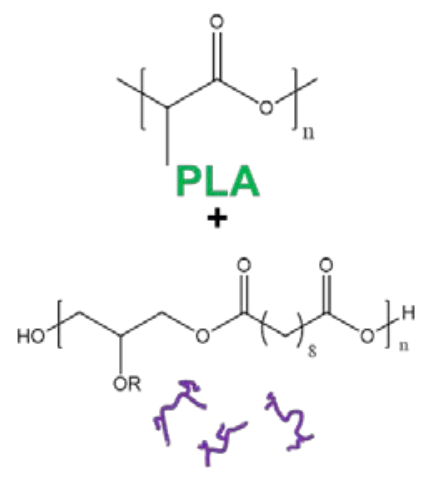

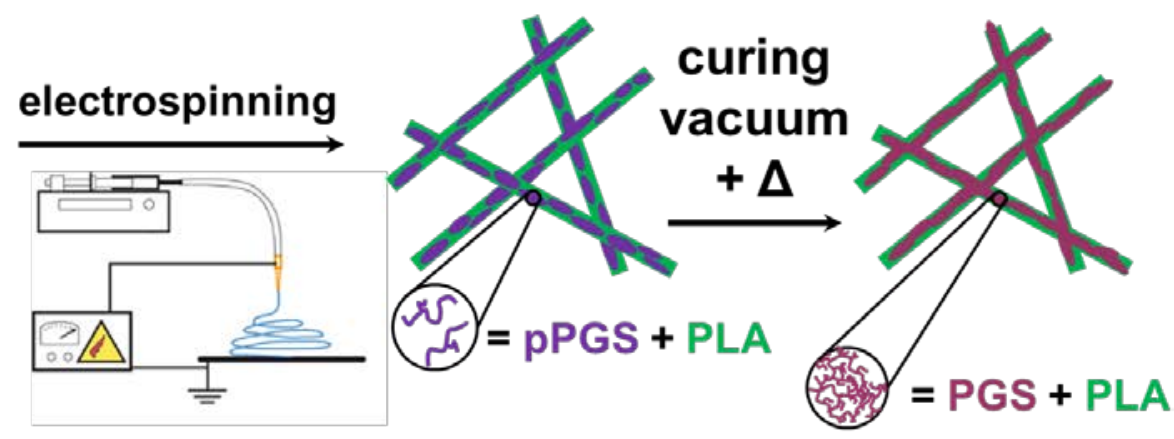

pPGS prepolymer
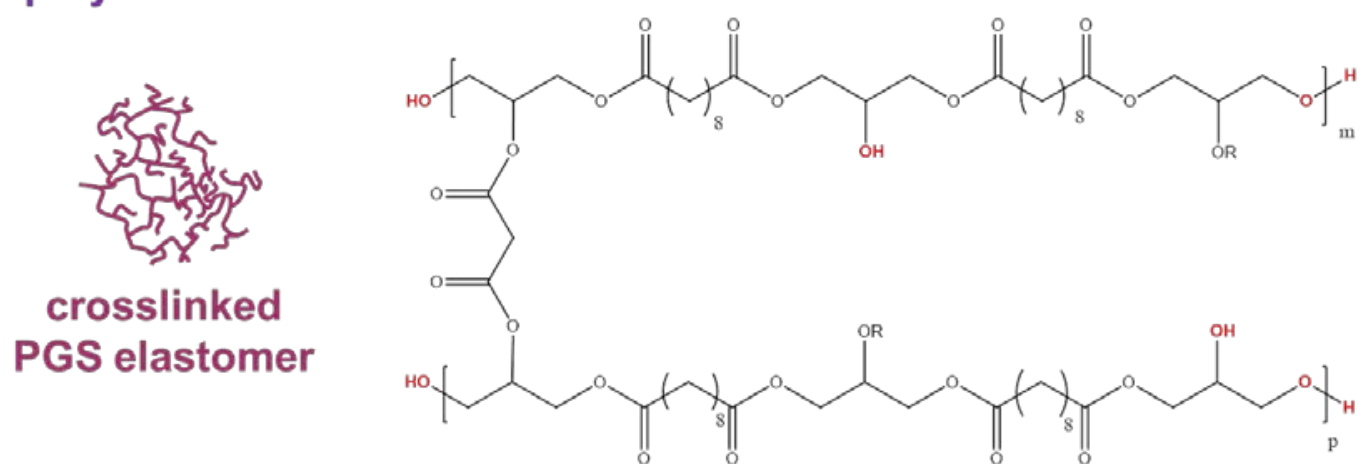

Figure 1. Representation of the structure of pPGS prepolymer, PGS elastomer and PLA and procedure of elaboration. The soluble prepolymer is used for electrospinning. Then, the fibers containing the prepolymer are cured in order to fabricate fibers containing the crosslinked elastomer. 


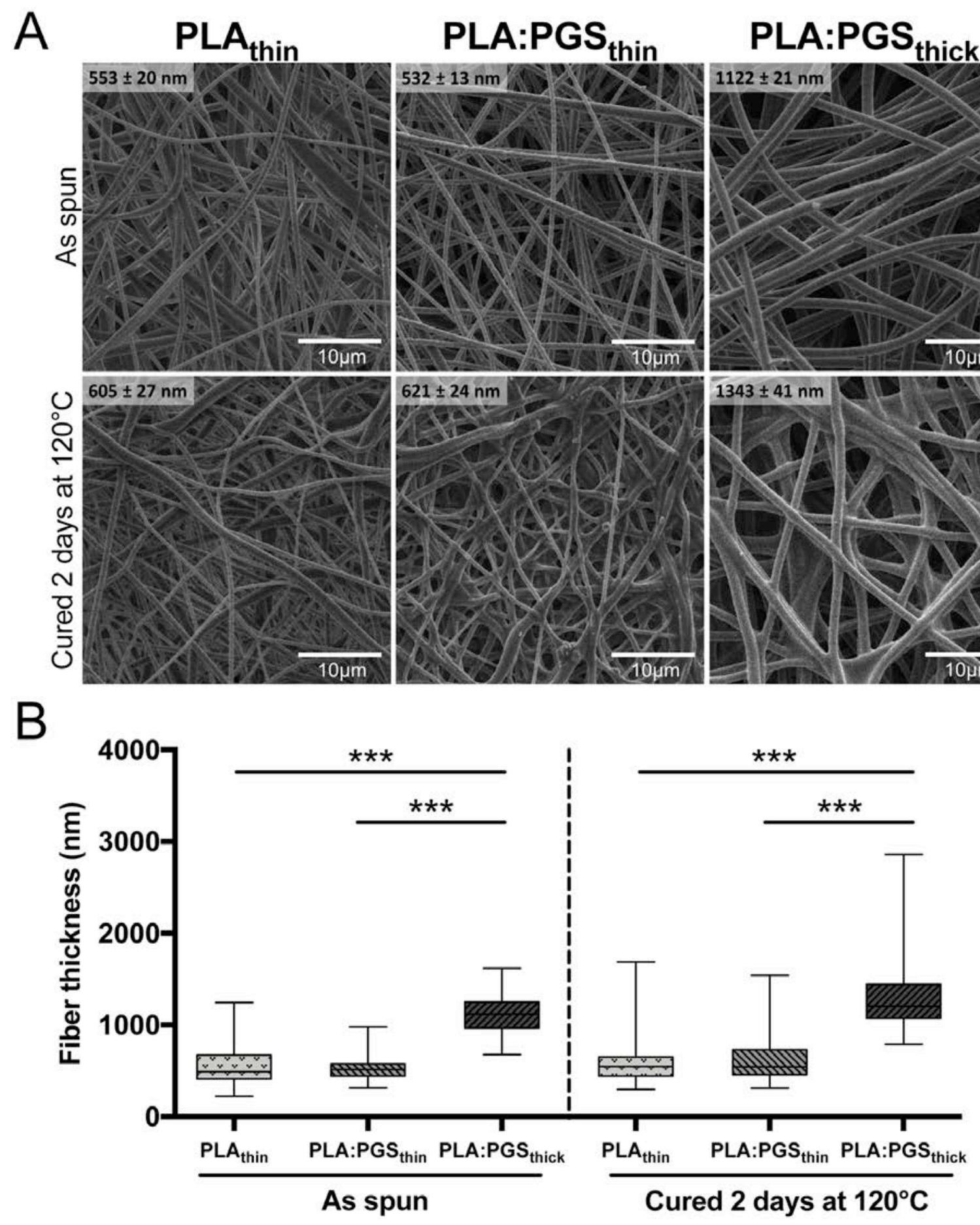

Figure 2. Morphology of the PLA and PLA:PGS electrospun fibers. SEM pictures (A) and fibers diameters (B) of PLA and PLA:PGS mats before and after crosslinking with 2 days of curing at $120^{\circ} \mathrm{C}\left(100\right.$ measurements on each sample). Results for the mats after curing at $90^{\circ} \mathrm{C}$ and after sterilization are given in Figure S2 and S4. PLA:PGS mats were obtained with 30\%pPGS:70\%PLA in DCM:DMF (6:4) (PLA:PGS thin $)$ or 30\%pPGS:70\%PLA in DCM:DMF (7:3) (PLA:PGS thick). PLA mats were obtained with 10\% PLA in DCM:DMF (6:4) solution (PLA $\left.\mathrm{P}_{\text {thin }}\right)$. The lower and upper borders of the box are the quartiles, the line in the box is the median and the end of whiskers represent the minimum and the maximum of the data. $* * * p$ value $<0.001$. 
After crosslinking at $90^{\circ} \mathrm{C}$ or $120^{\circ} \mathrm{C}$, PLA:PGS fibers are slightly fused together at the contact points, but the mats are still fibrous (Figure 2A and Figure S2). This effect is due to pPGS which can flow during curing at these temperatures because of its low viscosity before the crosslinking. This phenomenon spread the diameters distribution to higher values without changing significantly the mean values, as shown in Figure 2B and S3. The diameter of thin fibers is still in the range of $600 \mathrm{~nm}$ while cured thick fibers have a diameter in the range of $1300 \mathrm{~nm}$. This fusion however has also a slight impact on the porosity of the mats, measured by gravimetry. Indeed, PLA:PGS thin mats have a porosity of $\sim 77 \%$ which decreases to $\sim 49 \%$ after curing at $120^{\circ} \mathrm{C}$, while PLA:PGS thick mats porosity decreases from $\sim 85 \%$ to $\sim 62 \%$ after curing at $120^{\circ} \mathrm{C}$.

The PLA fibers are not melted at all. Again, the crosslinking step does not modify significantly the mean fibers diameters or the porosity of the mats which stays of $\sim 77 \%$ even after curing. Besides, the morphology of cured fibers is not modified by sterilization by autoclave, as shown in supplementary information (Figure S4). Moreover, the sterilization does not degrade PLA polymer. Indeed, size exclusion chromatography analyses gave the same number-average molar mass $\left(\mathrm{M}_{\mathrm{n}}\right)$ and mass-average molar mass $\left(\mathrm{M}_{\mathrm{w}}\right)$ of PLA in the as spun fibers, sterilized fibers and cured and sterilized fibers (see Figure S5 in supplementary information).

\subsection{Crystallinity of the PLA and PLA:PGS mats}

Although the PLA used in this study is made from 95\% L-lactic acid and 5\% D-lactic acid, it is capable of crystallizing. In particular, it was observed that PLA-containing membranes undergo shrinkage during annealing or sterilization, possibly showing crystallization. DSC measurements were thus carried out to understand the phenomenon.

Membranes were first analyzed as spun, for thick and thin fibers, with or without pPGS. The thermograms of the first heating run show several phenomena (Figures S6A-B in Supporting Information). Between $0{ }^{\circ} \mathrm{C}$ and $50^{\circ} \mathrm{C}$, several endothermic peaks due to PGS moieties melting transitions are observed, in accordance with literature. ${ }^{22}$ The thermal transitions at higher 
temperature are only due to PLA. The glass transition temperature $\left(\mathrm{T}_{\mathrm{g}}\right)$ is observed around $60^{\circ} \mathrm{C}$ for pure PLA fibers and for PLA:PGS fibers. The absence of significant shift of PLA's $\mathrm{T}_{\mathrm{g}}$ points out that PGS and PLA coexist in separated domains. PLA's melting point $\left(\mathrm{T}_{\mathrm{m}}\right)$ is visible close to $150^{\circ} \mathrm{C}$ for each sample.

Between $\mathrm{T}_{\mathrm{g}}$ and $\mathrm{T}_{\mathrm{m}}$, an exothermic peak is noticed. According to the literature, this peak is due to cold crystallization. ${ }^{23}$ During the electrospinning process, solidification occurs too fast to let PLA crystallize completely. A metastable sate is thus observed for PLA after electrospinning. But during the heating process of DSC, molecular chains of PLA get enough thermal energy to organize in crystallites. Morel et al. ${ }^{24}$ showed that the cold crystallization temperature $\mathrm{T}_{\mathrm{cc}}$ is lower for thinner PLA fibers because the molecular orientation is higher: the crystallinity is thus higher in thin fibers. These results were confirmed by our measurements on PLA:PGS thin and thick fibers. In addition, it is interesting to compare the crystallinity of PLA just after electrospinning, namely before cold crystallization $\left(\chi_{c}^{\text {before cc }}\right)$, and after cold crystallization occurring during DSC heating run $\left(\chi_{c}^{\text {after }} \mathrm{cc}\right)$. The values are calculated according to equations (2) and (3).

$$
\begin{aligned}
& \chi_{c}^{\text {before } c c}=\frac{\Delta H_{m}-\Delta H_{c}}{\Delta H_{m}^{100 \%}} \times \frac{100}{\% P L A} \\
& \chi_{c}^{\text {after } c c}=\frac{\Delta H_{m}}{\Delta H_{m}^{100 \%}} \times \frac{100}{\% P L A}
\end{aligned}
$$

With $\% P L A$ the wt.\% of PLA in the final fibers (70\% for the PLA:PGS fibers), $\Delta H_{m}$ the melting enthalpy, $\Delta H_{c}$ the enthalpy of cold crystallization and $\Delta H_{m}^{100 \%}$ the melting enthalpy of $100 \%$ crystalline PLA equal to $93 \mathrm{~J} / \mathrm{g}^{25}$

Furthermore, the comparison of $\chi_{c}$ before and after cold crystallization shows that PLA is twice as crystalline after cold crystallization as before: $\chi_{c}$ starting between $15 \%$ to $20 \%$ before cold crystallization and reaching $30 \%$ to $40 \%$ after. However, after sterilization, the same fibers do not show a cold crystallization anymore. During autoclave sterilization, the fibers are indeed heated at $120^{\circ} \mathrm{C}$, a temperature higher than cold crystallization temperature $\left(80-90^{\circ} \mathrm{C}\right)$ 
leading to PLA crystallization and the resulting shrinkage of the scaffolds after their sterilization.

Moreover, the same phenomenon is observed after the crosslinking step. The results after curing at $120^{\circ} \mathrm{C}$ are given in Table 1 but the same tendency was observed after curing at $90^{\circ} \mathrm{C}$, as shown is Supporting Information (see Table S1). All the samples are melting at $150^{\circ} \mathrm{C}$ without any prior cold crystallization during the DSC heating ramp, confirming that crystallization occurred during annealing. This behavior is also observed for cured and sterilized samples. The crystallization of PLA fibers during an annealing process was already studied by Ribeiro et $a l .{ }^{26}$ who found similar results.

Table 1: Glass transition temperature $\left(T_{g}\right)$, cold crystallization temperature $\left(T_{c}\right)$, melting temperature $\left(\mathrm{T}_{\mathrm{m}}\right)$ and crystallinity $\left(\chi_{\mathrm{c}}\right)$ of PLA in the fibers, before and after curing at $120^{\circ} \mathrm{C}$, sterilized or not.

\begin{tabular}{|c|c|c|c|c|c|c|}
\hline & & $\mathbf{T}_{\mathrm{g}}\left({ }^{\circ} \mathrm{C}\right)$ & $\mathbf{T}_{\mathbf{c}}\left({ }^{\circ} \mathbf{C}\right)$ & $\mathbf{T}_{\mathrm{m}}\left({ }^{\circ} \mathbf{C}\right)$ & $\chi_{c}^{\text {before } c c}$ & $\chi_{c}^{\text {after } c c}$ \\
\hline \multirow{4}{*}{ As spun } & PLA:PGS thin & 59 & 81 & 149 & 0.20 & 0.36 \\
\hline & PLA:PGS thick & 59 & 83 & 149 & 0.14 & 0.31 \\
\hline & $\mathrm{PLA}_{\text {thin }}$ & 61 & 89 & 150 & 0.16 & 0.31 \\
\hline & $\underline{\text { PLA }} \underline{\text { thin }} \underline{\text { sterilized }}$ & 61 & - & 151 & 0.32 & 0.32 \\
\hline \multirow{2}{*}{ Cured : } & PLA:PGS thin & 61 & - & 150 & 0.34 & 0.34 \\
\hline & PLA $_{\text {thin }}$ & 60 & - & 150 & 0.34 & 0.34 \\
\hline $120^{\circ} \mathrm{C}$ & $\underline{\text { PLA }} \underline{\underline{t h i n}} \underline{\text { sterilized }}$ & 62 & - & 150 & 0.35 & 0.35 \\
\hline
\end{tabular}



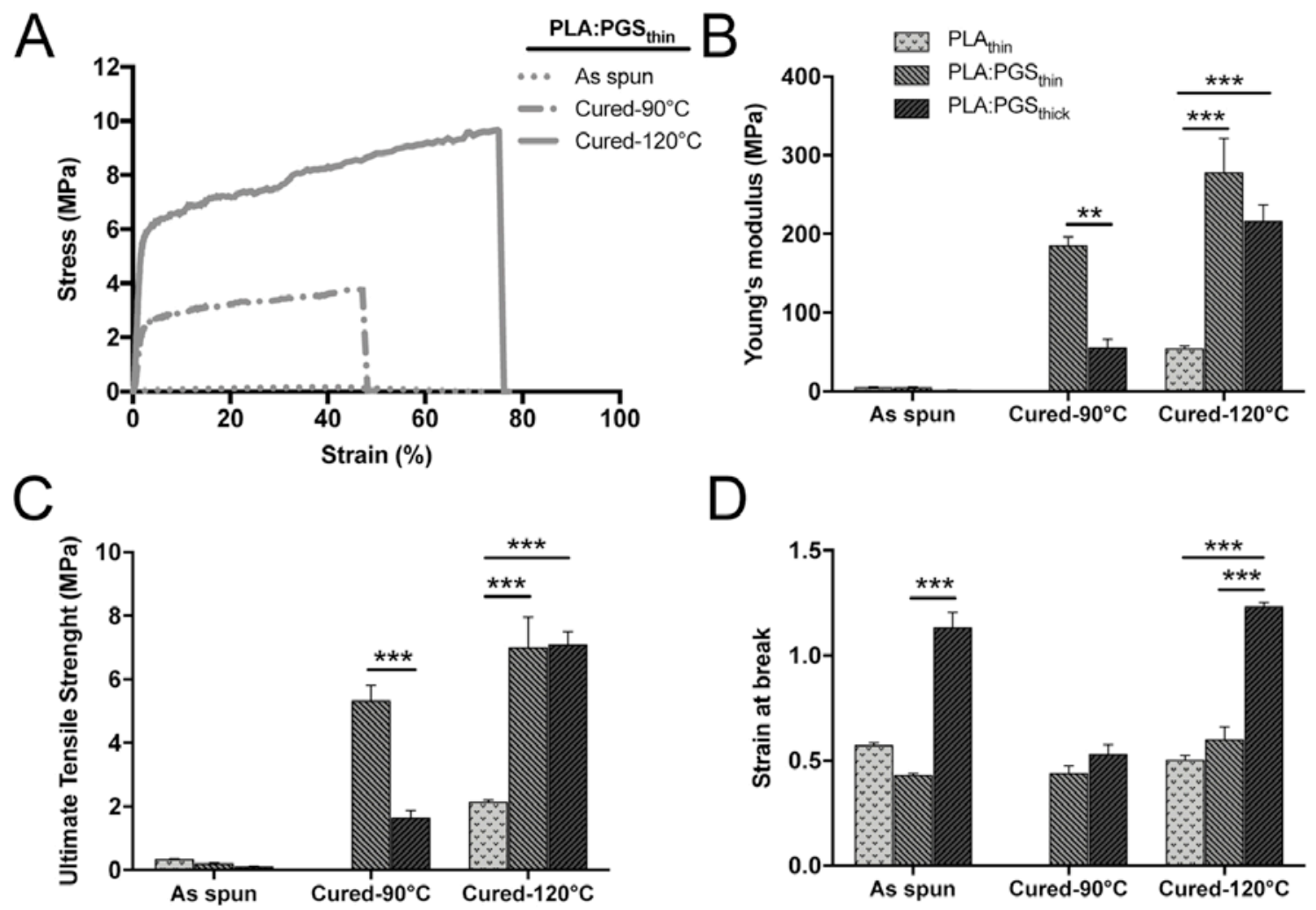

$\mathrm{D}$

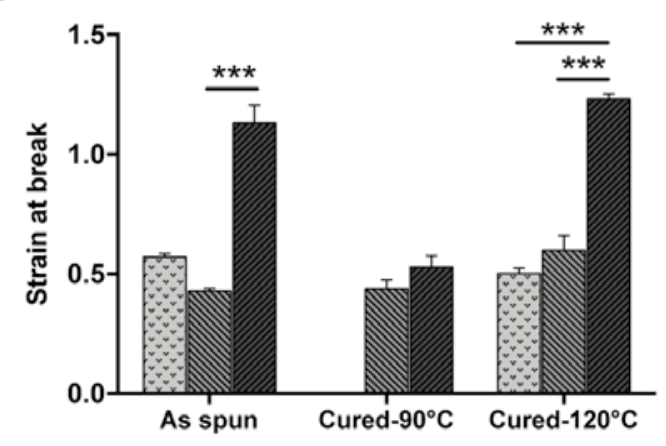

Figure 3. Mechanical properties of the PLA and PLA:PGS mats. Representative evolution of stress-strain curves upon curing for PLA:PGS ${ }_{\text {thin }}$ fibers (A). Evolution of Young's modulus (B); Ultimate tensile strength (C) and strain at break upon curing (D) of PLA thin, PLA:PGS thin and PLA:PGS thick $_{\text {fibers }}(\mathrm{n}=5) .{ }^{* *} \mathrm{p}<0,01,{ }^{* * *} \mathrm{p}<0,001$.

\subsection{Mechanical properties of the PLA and PLA:PGS mats}

For the desired application, the scaffold's mechanical strength should be sufficient to facilitate the handling and the suture process for cardiac applications. Moreover, the scaffold's therapeutic properties can be enhanced by its mechanical properties if they match myocardium properties, namely a Young's modulus comprised between 200 and $500 \mathrm{kPa}$ at the end of diastole. ${ }^{27}$ Thus, it is necessary to characterize the membranes' mechanical behavior. Uniaxial tensile tests experiments were conducted on the fibrous mats and stress-strain curves were drawn. Typical evolution of the stress upon strain after different crosslinking steps on

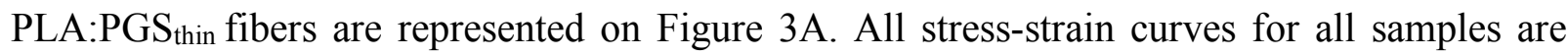
given in supplementary information (see Figures S7, S8 and S9). This figure shows clearly

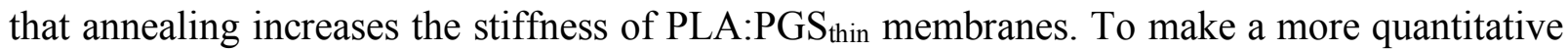


comparison, the Young's modulus (E) (Figure 3B) was determined for different formulation and crosslinking parameters. Despite many trials, it was almost impossible to prevent the break of the cured samples at the clamps, certainly because of the thinness of the membranes after shrinkage during annealing. The Ultimate Tensile Strength (UTS) and the strain at break ( $\left.\varepsilon_{\text {break }}\right)$ values are consequently only reliable for uncured samples. However, the values for cured samples indicate the minimal strain and stress the samples can undergo, and are therefore given in Figure 3C and Figure 3D.

It can be noticed that the curing step results in higher E and UTS values, even higher when the annealing temperature is higher. Moreover, Young's moduli and UTS of PLA:PGS thick fibers

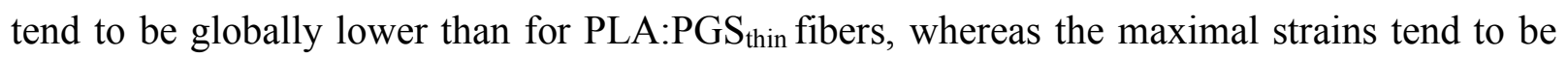
larger. Finally, tensile tests indicate that PLA:PGS mats, and in particular PLA:PGS thin $_{\text {mats }}$ are stiffer than pure PLA ones.

\subsection{Evaluation of the hydrophilicity of PLA and PLA:PGS mats}

Cell adhesion, a feature of great importance for tissue engineering applications, can be enhanced by the scaffold's hydrophilicity. ${ }^{28,29}$ However, in the present study, PLA, a hydrophobic polymer, was used. PGS should be more hydrophilic ${ }^{15}$, even if its hydrophilicity depends strongly on the presence of remaining unreacted alcohol or carboxylate groups and thus on its crosslinking degree. Therefore, the addition of PGS was expected to improve the hydrophilicity of the scaffolds. Sessile drop method was thus used to characterize the wettability of the membranes.

Different surface's behaviors were noticed. The apparent water contact angle (WCA) was static on pure PLA membranes or on PLA:PGS membranes cured at $120^{\circ} \mathrm{C}$. The mean values are given in Figure 4A. The annealing step does not modify the hydrophilicity of pure PLA mats, which showed a WCA of $128 \pm 6^{\circ}$ before curing and $127 \pm 4^{\circ}$ after. For thin fibers, the presence of PGS leads to a slight decrease in the WCA value, while a strong hydrophobic behavior is 


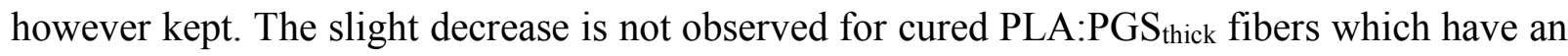
WCA close to PLA fibers WCA.

On the contrary, PLA:PGS scaffolds, uncured or cured at $90^{\circ} \mathrm{C}$, absorb the water droplet, which is illustrated by the decrease of the WCA during time. This behavior reveals their sufficient hydrophilicity to allow water absorption in the porous membrane. Nevertheless, because the WCA is continuously evolving upon time, it is not possible to define a reliable WCA value to compare the hydrophilicity of the different mats. The decrease in WCA was thus recorded upon time, as shown in Figure 4B. The initial value was not selected as a comparable value because it was strongly dependent on the strength applied during the droplet deposition. Furthermore, the end of the curve and the potential plateau value is influenced by the volume available for the water in the mat, namely its surface and thickness.

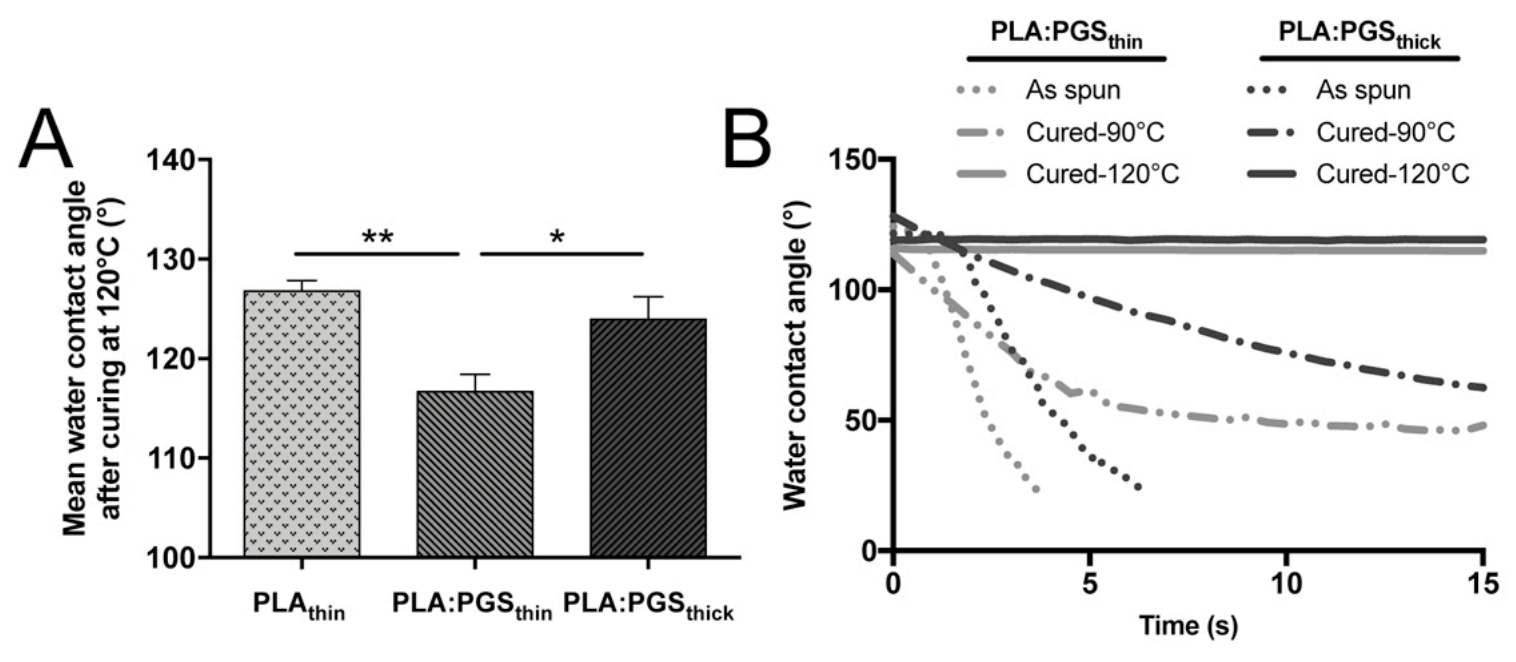

Figure 4. Hydrophilicity of the PLA and PLA:PGS mats. Mean apparent water contact angle (WCA) of PLA thin, PLA:PGS $\mathrm{PS}_{\text {thin }}$ and PLA:PGS thick mats after curing at $120^{\circ} \mathrm{C}(\mathrm{A})(\mathrm{n}=10)$. Typical evolution of the WCA during time on PLA:PGS thin $_{\text {and PLA:PGS }}$ anick mats for different curing steps (B). ${ }^{*} p<0,05, * * p<0,01$.

It can be noticed from Figure 4B that the curves present up to three domains, this evolution corresponding to transition from an air-pocket regime to a penetration regime. The air-pocket regime depends strongly on the impact force applied during droplet deposition and the surface roughness of the mat. If the force is too weak and the membrane is very fluffy, which may be 
the case for as spun fibers, the droplet visibly remains at the top of the fibers during a few seconds, confining air pockets in the mat. It results in a constant WCA. The droplet starts then to spread at the surface of the mat while imbibing it thanks to capillarity forces. ${ }^{30}$ WCA decreases under the effect of these two phenomena. At a certain point, the droplet's spreading stops and only penetration occurs: WCA decreases more slowly. This last stage with only penetration is confirmed by the constant value of droplets' diameters.

Figure 4B shows that uncured PLA:PGS mats absorb water faster than cured samples. Furthermore, it seems that increasing the crosslinking temperature leads to a slower absorption, until no absorption after annealing at $120^{\circ} \mathrm{C}$. Finally, harsh annealing conditions (2 days at $120^{\circ} \mathrm{C}$ ) decrease hydrophilicity differences between PLA and PLA:PGS materials.

Besides, the membranes were coated by matrigel before cell seeding. The hydrophilicity of matrigel coated patches was also characterized (Figure 6C). As the membranes absorb water, WCA was registered upon time; Figure $6 \mathrm{C}$ shows that hydrophilicity of PLA $\mathrm{A}_{\text {thin }}$ and PLA:PGS thin $_{\text {fibers }}$ crosslinked at $120^{\circ} \mathrm{C}$ is dramatically improved after coating as the WCA decreases significantly upon time.

In order to prove that PGS is on the fiber surface pristine PLA thin and non-crosslinked PLA:PGS thin membranes were observed by SEM before and after plunging them in ethanol. Figure 5a and 5c show that both PLA:PGS $\mathrm{P}_{\text {thin }}$ and PLA $_{\text {thin }}$ fibers are initially rough with visible protuberances in the case of PLA:PGS thin fibers. After thermal annealing and washing in ethanol, PLA $A_{\text {thin }}$ fibers appear a little bit smoother than before their treatment (Figure 5d).

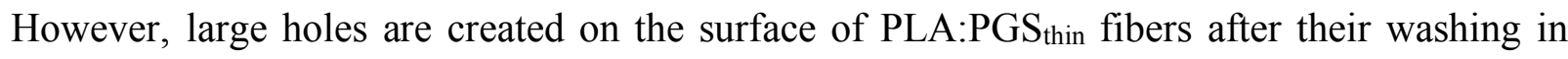
ethanol due to the selective extraction of PGS (Figure 5b) proving that a high amount of PGS is located on the surface of the fibers. 

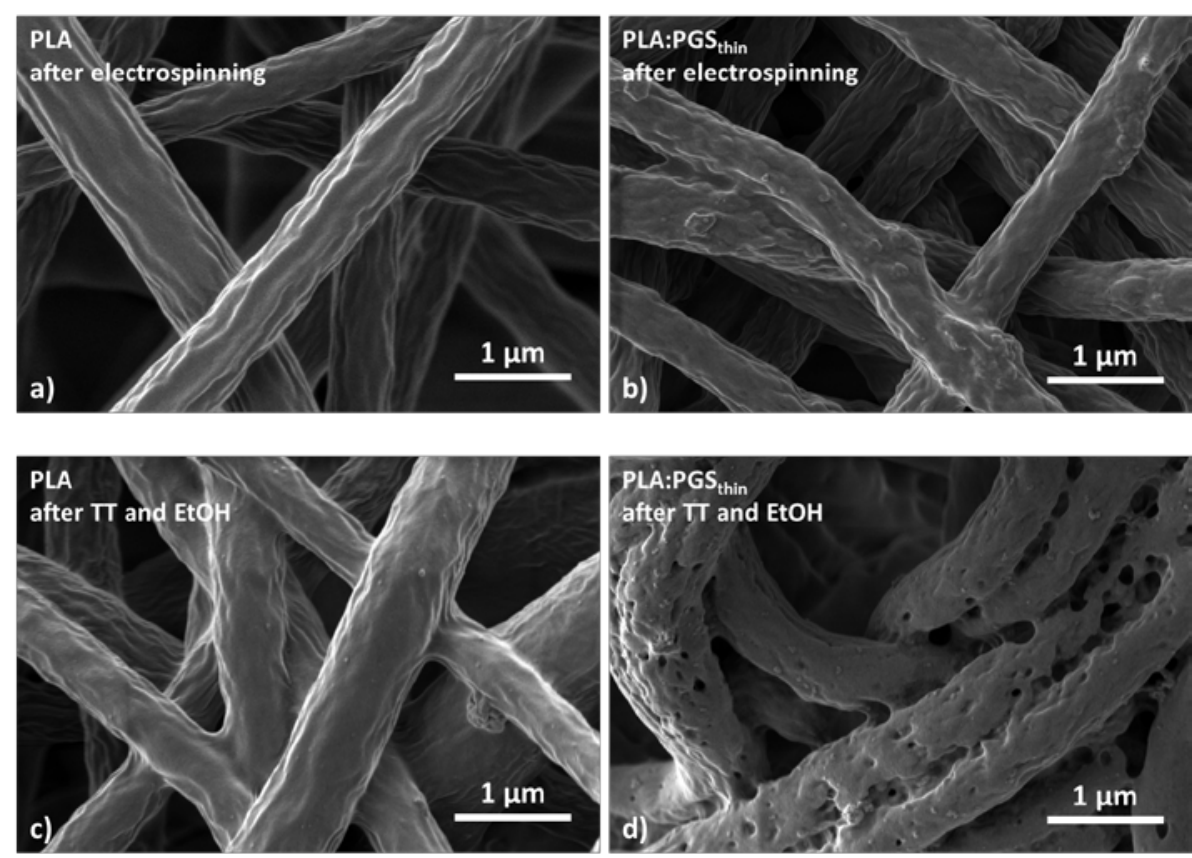

Figure 5. SEM observations of membranes. a) PLA thin membrane just after electrospinning. b) PLA:PGS thin membrane just after electrospinning. c) PLA thin membrane after thermal annealing at $90^{\circ} \mathrm{C}$ and washing in ethanol. d) PLA:PGS ${ }_{\text {thin }}$ membrane after thermal annealing at $90^{\circ} \mathrm{C}$ and washing in ethanol.

\subsection{Cellularization of PLA and PLA:PGS mats and influence of matrigel coating}

To assess the cytocompatibility of the PLA and PLA:PGS mats for the biological application, neonatal rat cardiomyocytes were seeded on nude or matrigel-coated PLA $\mathrm{A}_{\text {thin }}$ or PLA:PGS $\mathrm{S}_{\text {thin }}$ mats. Immunostaining of $\alpha$-actinin, a surrogate marker of functional cardiomyocytes, ${ }^{31}$ was used to evaluate the cell attachment and the growth after 3 days of culture on these mats. As demonstrated in Figure 6, in the absence of matrigel coating, neonatal cardiomyocytes were

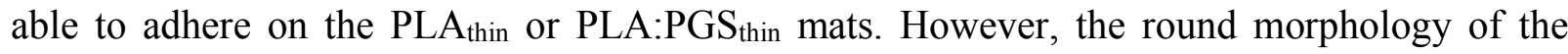
cardiomyocytes showed the difficulty of the cells to spread on nude-fibers as shown by Figures 6A-5B and 6D. In contrast, cardiomyocytes seeded on matrigel coated-mats exhibited physiological shape with a well-organized sarcomeric structure as observed by $\alpha$-actinin immunostaining (Figures 6A-5B) and by SEM images (Figure 6D-6E). The effect of the

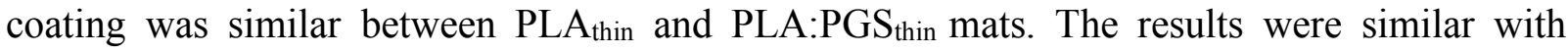


laminin coating. As shown in Figure 6F, the cardiomyocytes adhere and spread well on the laminin coated-mats.

As matrigel may form a continuous film at the surface of the samples, samples without cells were also analyzed by SEM to evaluate the porosity of the mats after functionalization (Figure 6A-6B). SEM images highlighted some film parts remain on PLA fibers, but not on PLA:PGS fibers, where matrigel certainly wrap the fibers. This could indicate a better interaction of matrigel with PGS than with PLA. Previous hydrophilicity characterization of coated materials (Figure 6C) confirm that Matrigel is present, coating each fiber individually.

Finally, to determine the capacity of neonatal cardiomyocytes to growth and to infiltrate in the

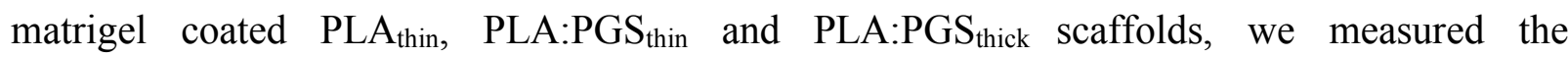
cardiomyocyte surface area and perimeter, cardiomyocyte length-to-width ratio, sarcomere length and the maximum $\mathrm{Z}$ position of the cardiomyocytes after 6 days of culture (Figure 7). As demonstrated in Figure 7B, we noticed an increase in the cardiomyocyte size (surface and perimeter) on the PLA:PGS thin mats in comparison to PLA thin and PLA:PGS thick $_{\text {after }} 6$ days of culture independently of the curing temperature. Concerning sarcomere length, the significant increase of sarcomere length were observed with the cardiomyocytes cultured on PLA:PGS thin $_{\text {in }}$ mats cured at $120^{\circ} \mathrm{C}$ in comparison to $\mathrm{PLA}_{\text {thin }}$ and $\mathrm{PLA}: \mathrm{PGS}_{\text {thick }}$ cured at $120^{\circ} \mathrm{C}$. Furthermore, the cell colonization into the mats was increased by 2-fold with PLA:PGS $\mathrm{Phin}_{\text {cured }}$ at $120^{\circ} \mathrm{C}$ than PLA thin (Figure 7C). These findings suggest an higher capacity of the PLA:PGS thin mats, especially cured at $120^{\circ} \mathrm{C}$, to support the spreading of the cardiomyocytes in vitro. 


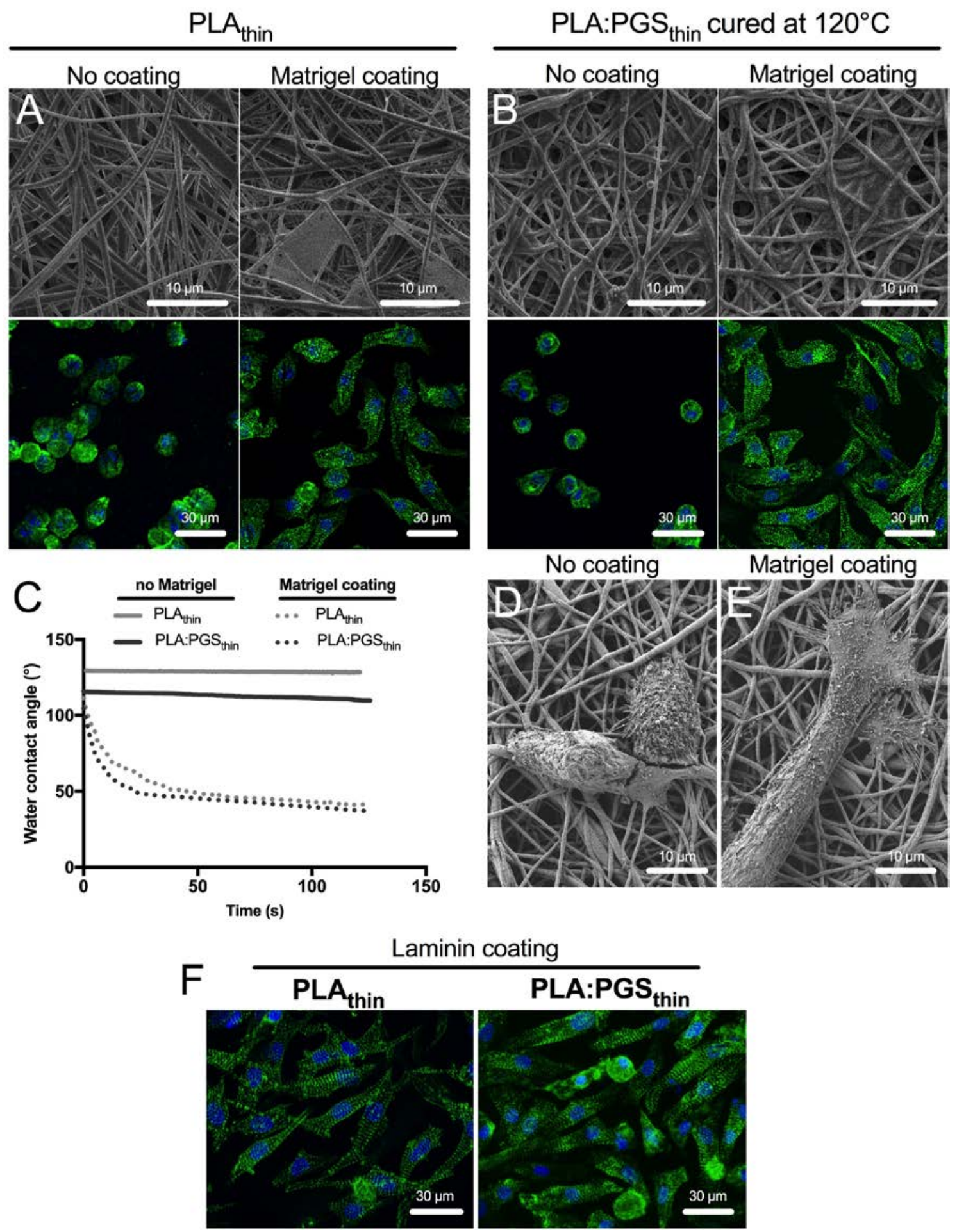

Figure 6. Influence of surface coating on the hydrophilicity and cellularization of the PLA and PLA:PGS mats. SEM images of nude or matrigel-coated PLA thin (A, upper panel) and

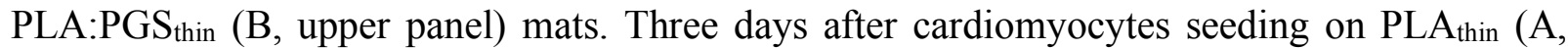
lower panel) or PLA:PGS thin $(\mathrm{B}$, lower panel) mats, cardiomyocytes were immunolabeled with the antibody against $\alpha$-actinin (green). Nuclei appear blue due to Hoescht 33342 staining. Typical evolution of the WCA during time on nude or matrigel-coated PLA thin $_{\text {and }}$ PLA:PGS thin mats (C). SEM images of nude (D) or matrigel-coated cellularized PLA:PGS thin $_{\text {th }}$ (E) mats. Influence of laminin on the cellularization of the PLA $A_{\text {thin }}$ and PLA:PGS thin mats $(F)$. Three days after cardiomyocytes seeding, cardiomyocytes were immunolabeled with the antibody against $\alpha$-actinin (green). Nuclei appear blue due to Hoescht 33342 staining. 


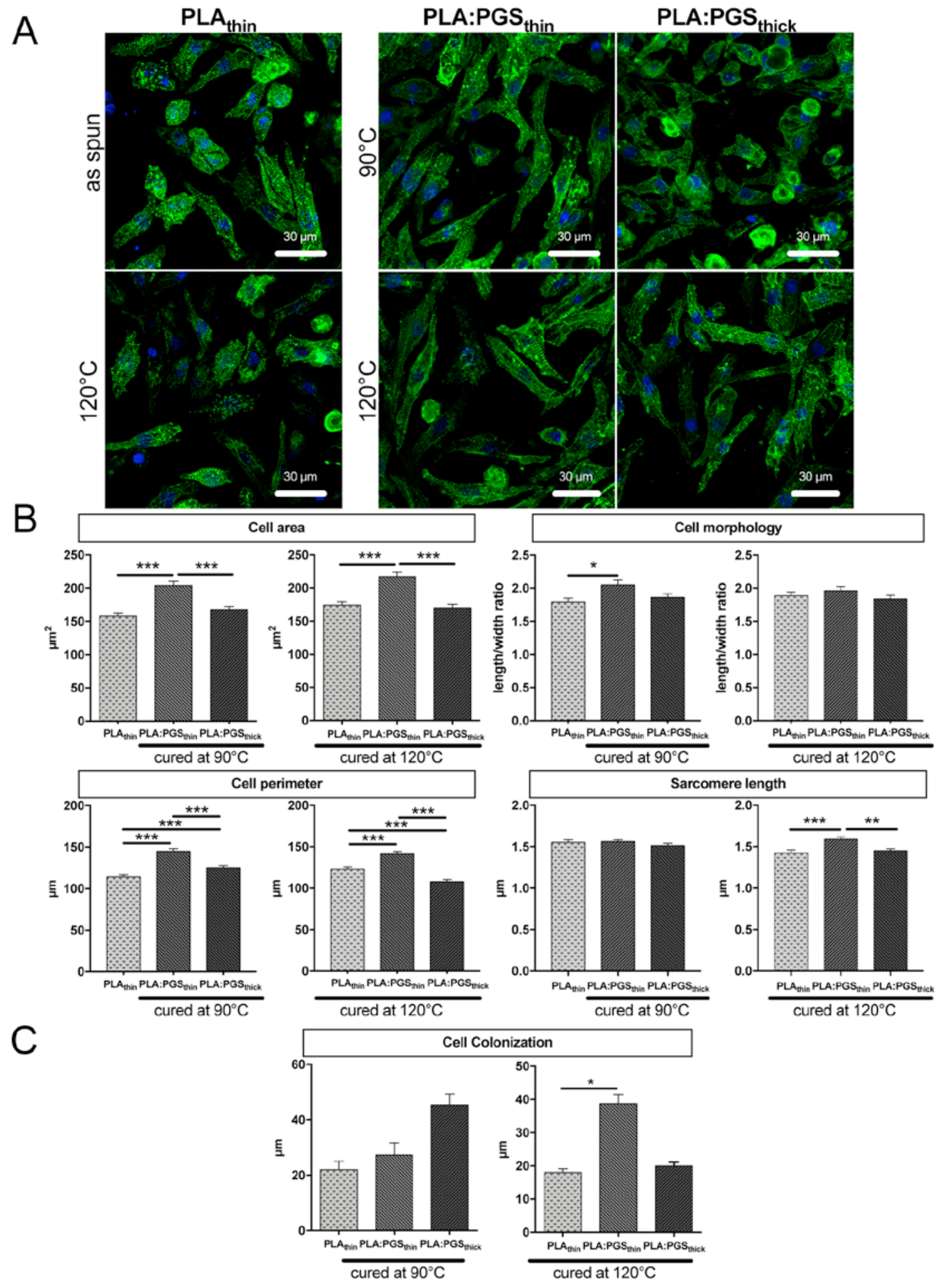

Figure 7. Cellularization of the PLA and PLA:PGS mats with neonatal rat cardiomyocytes. Six days after cardiomyocytes seeding on matrigel-coated PLA thin, PLA:PGS thin $_{\text {th }}$ and PLA:PGS thick $_{\text {the }}$ cured at $90^{\circ} \mathrm{C}$ or $120^{\circ} \mathrm{C}$, cardiomyocytes were immunolabeled with the antibody against $\alpha$ actinin (green) (A). Nuclei appear blue due to Hoescht 33342 staining. Mean of the cardiomyocyte surface area, cardiomyocyte perimeters, cardiomyocyte length-to-width ratios $(n=3, n>125-200$ cells per condition) and sarcomere length $(n=3, n>30$ sarcomere per condition) were measured 6 days after cell culture on the mats (B). The maximum $\mathrm{Z}$ position of the cardiomyocytes into the mats were measured 6 days after cell culture $(n=3)(C)$. Values are given as means \pm standard error of the mean. ${ }^{*} p<0.05 * * * p<0.001$. 


\subsection{Biocompatibility of the PLA and PLA:PGS mats}

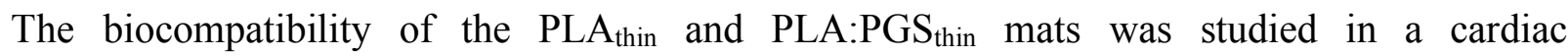
environment, after implantation of acellular mats on the surface of the heart of healthy Swiss mice. Previous studies demonstrated that PGS has a good biocompatibility. ${ }^{14,32}$ In this study, acellular PLA thin and PLA:PGS thin $_{\text {mats }}$ were sutured on the surface of the heart of healthy swiss mice for 7 days and 28 days. We first evaluated the integrity of the mats by polarized microscopy and hematoxylin-eosin staining. As demonstrated in Figures 8, after 7 and 28 days

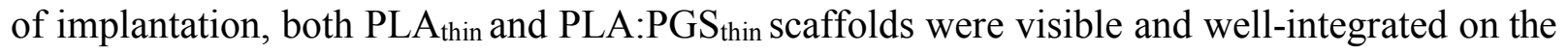
ventricle. 


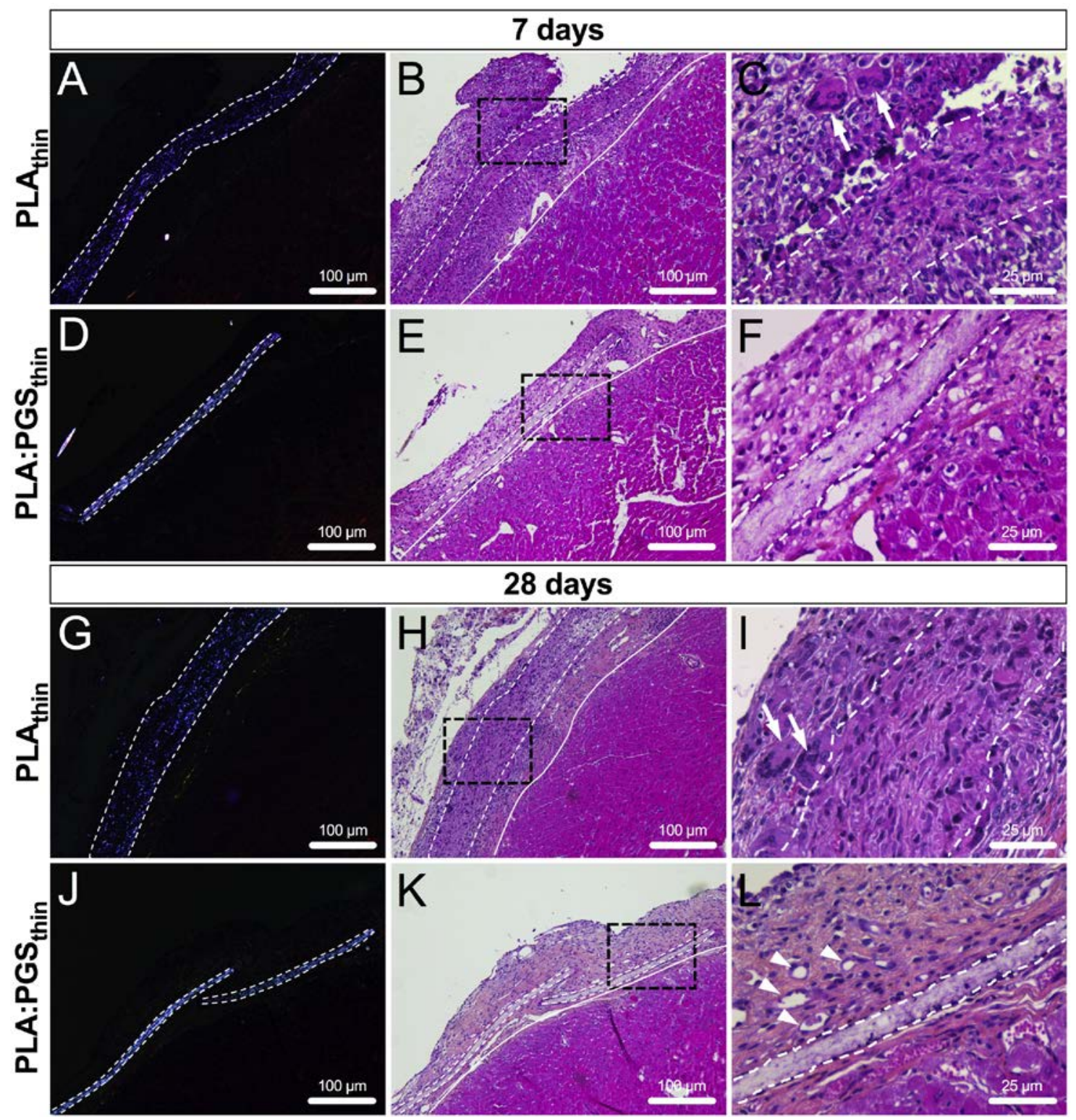

Figure 8. Biocompatibility of the PLA and PLA:PGS mats after implantation on the surface of the heart of healthy mice. The residual mats was visualized by polarized microscopy $(A, D, G$ and $\mathrm{J}$ ) and general morphology of the heart by hematoxylin-eosin staining after 7 days (B-C and E-F) and 28 days (H-I and K-L) of implantation of acellular PLA thin $(A-C$ and G-I) and PLA:PGS thin $\left(\mathrm{D}-\mathrm{F}\right.$ and J-L) cured at $120^{\circ} \mathrm{C}$ mats. Arrows indicate the accumulation of multinucleated giant cells and arrowheads indicate capillaries. White solid lines show the border between the grafted mats and heart. White dot lines represent residual mats on the surface of the heart. Black dot lines in B, E, H and $\mathrm{K}$ show higher magnification area in $\mathrm{C}, \mathrm{F}, \mathrm{I}$ and L, respectively.

In contrast to PLA:PGS thin, $_{\text {PLA }}$ thin scaffolds have a more diffuse structure after implantation which were visualized by polarized microscopy (Figures 8 ). The diffuse structure of the PLA $_{\text {thin }}$ mat fibers was also accompanied by cell infiltration composed predominantly of 
mononuclear cells with the accumulation of multinucleated giant cells at the grafted area (see arrows in Figure 8C) demonstrating the presence of moderate foreign body reaction. The situation remains similar 28 day after implantation (Figure 8I), foreign body reaction persists with PLA $_{\text {thin }}$ mats whereas PLA:PGS thin mats were perfectly integrated on the surface of the ventricle and only a few mononucleated cells are visualized in the mats demonstrating a perfect biocompatibility of this scaffold. As demonstrated in Figure 8L and Figure 9, PLA:PGS thin $_{\text {in }}$ mats also induce the formation of the new vessels at the grafted area (see arrowheads in Figure 8L and arrows in Figure 9). The number of endothelial cells were quantified at the grafted area after 28 days of implantation by caveolin $1 \alpha$ staining (Figure 9). Our results demonstrated that the number of caveolin $1 \alpha$ positive cells were significantly higher with PLA:PGS thin $_{\text {compared }}$ to $\mathrm{PLA}_{\text {thin }}$ mat $(314.1 \pm 24.3$ vs $168.9 \pm 28.9, p=0.018)$. The biocompatibility of PLA:PGS thin mat was also supported by Sirius red staining, as demonstrated in Figure 10, PLA:PGS thin mats induce less fibrosis in comparison to PLA thin mats after implantation on surface of the heart. Taken together, with a good integrity after 28 days and a low inflammatory response, PLA:PGS $\mathrm{P}_{\text {thin }}$ mats cured at $120^{\circ} \mathrm{C}$ present all characteristics to be a potential scaffold for cardiac tissue engineering. 

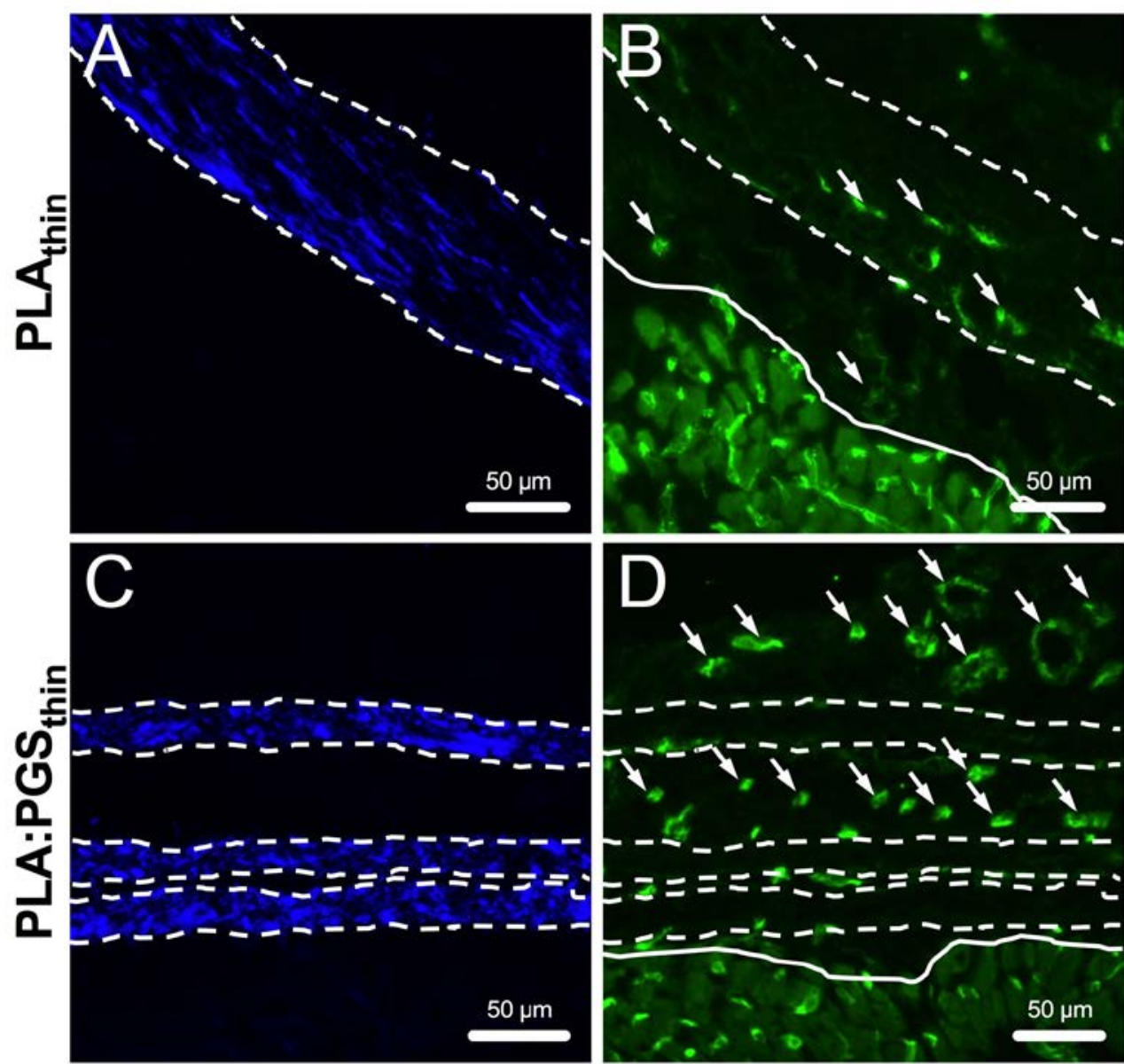

Figure 9. Biocompatibility of the PLA:PGS $\mathrm{P}_{\text {thin }}$ mats 28 days after implantation on the surface of the heart of mice. The residual mats were visualized by polarized microscopy ( $\mathrm{A}$ and $\mathrm{C}$ ) after implantation of acellular PLA $\mathrm{Athin}_{(\mathrm{A}-\mathrm{B}) \text { and PLA:PGS }}$ thin $(\mathrm{C}-\mathrm{D})$ cured at $120^{\circ} \mathrm{C}$ mats. Numerous vessels were identified at the grafted area as evidenced by caveolin $1 \alpha$ staining (see arrows in B and D). White dot lines represent residual mats on the surface of the heart. White solid lines show the border between the grafted mats and heart.
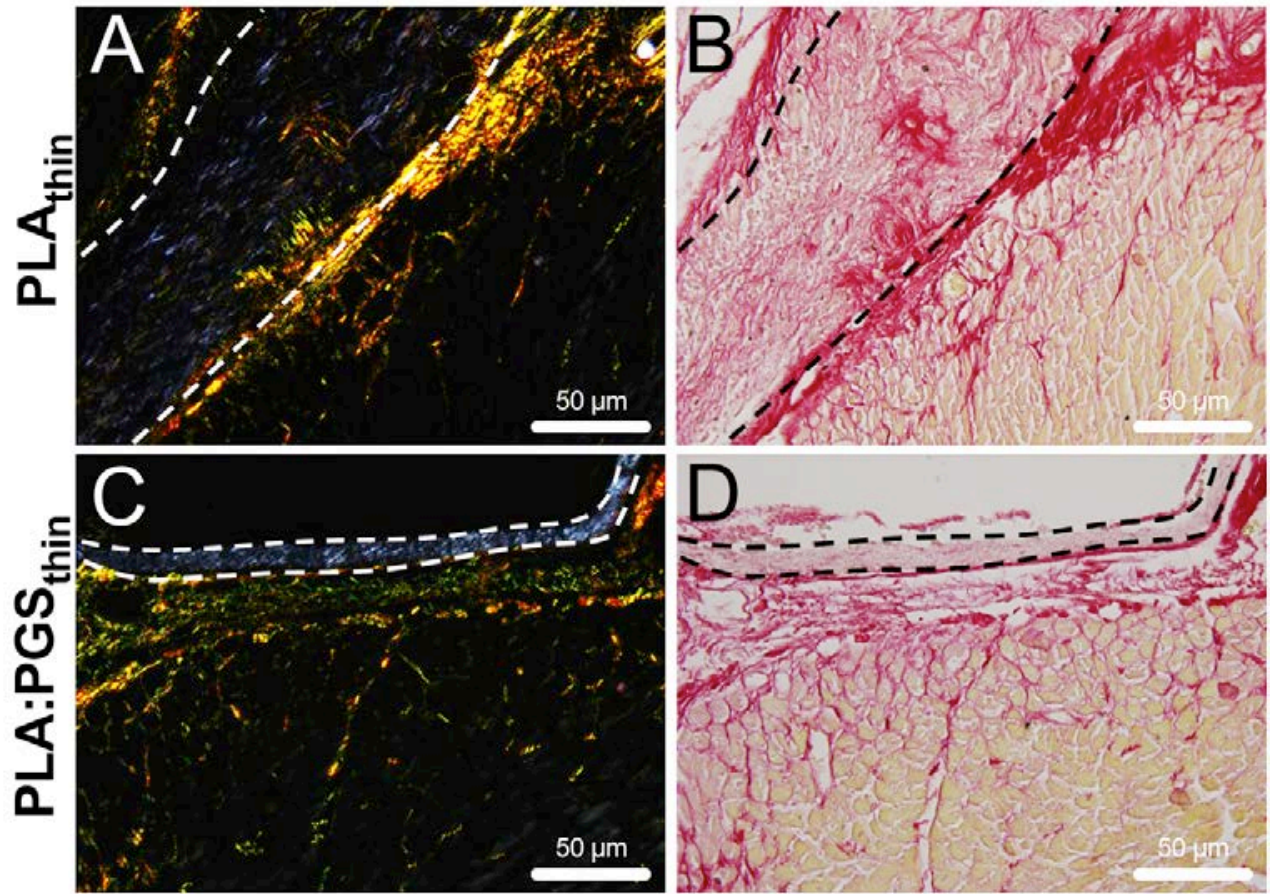
Figure 10. Assessment of cardiac fibrosis by Sirius red staining 28 days after implantation. The residual mats and fibrosis were visualized by polarized microscopy (A and C) and Sirius red staining (B and D) after 28 days of implantation of acellular PLA thin $(A-B)$ and PLA:PGS thin $(C-$ D) cured at $120^{\circ} \mathrm{C}$ mats. White dot lines represent residual mats on the surface of the heart.

\section{Discussion}

PGS is an attractive biopolymer for biological applications, especially for the cardiac bioengineering due to its Young's modulus matching heart's stiffness and its in vitro and in vivo compatibilities. ${ }^{16}$ However, PGS processing remains quite challenging by its thermoset elastomer properties. In our current study, we fabricated PLA:PGS blend electrospun nanofibers with varying parameters to evaluate the effect of fiber diameter and annealing temperature on the in vitro and in vivo cardiac response for bioengineering applications.

Three kinds of electrospun mat were prepared: pure PLA $A_{\text {thin }}$ mats, PLA:PGS thin $_{\text {mats }}$ with a fiber diameter in the range of $600 \mathrm{~nm}$, and PLA:PGS thick $_{\text {mats }}$ with a fiber diameter in the range of $1300 \mathrm{~nm}$, both PLA:PGS mats containing 30\% of PGS. Annealing of the mats at $90^{\circ} \mathrm{C}$ or $120^{\circ} \mathrm{C}$ for $48 \mathrm{~h}$ under vacuum was performed in order to allow the pPGS to crosslink resulting in PGS elastomer. The curing step had only a small impact on the morphology of the scaffold containing PGS, inducing a slight fusion of the fibers at crosspoints and moderate compaction of the mats due to the competition between pPGS flowing and crosslinking at high temperature. However, the curing step has an important impact on the molecular structure inside the fibers due to PLA crystallization and PGS crosslinking, which results in significant variation of the mechanical properties and hydrophilicity.

The PLA crystallinity of all mats increases from $15-20 \%$ to $35 \%$ after curing. PGS content in the fibers does not modify this value, indicating the coexistence of two separate polymeric phases in the fibers. Moreover, the same crystallinity is observed after sterilization of uncured PLA fibers. The crystallinity has an influence on the mechanical properties of the scaffolds. Indeed, as expected ${ }^{33}$, Young's modulus $\mathrm{E}$ of PLA $\mathrm{A}_{\text {thin }}$ mats increases from $4.4 \pm 2$ to $54 \pm$ 
$9 \mathrm{MPa}$ and ultimate tensile strength (UTS) increases from $0.20 \pm 0.06$ to $7.0 \pm 2 \mathrm{MPa}$, after curing at $120^{\circ} \mathrm{C}$. It is also responsible for a small shrinkage of the scaffold during curing.

The PGS crosslinking during annealing under vacuum is a consequence of the condensation reaction between remaining $-\mathrm{OH}$ and $-\mathrm{COOH}$ groups of the prepolymer. Therefore, it has an influence on the hydrophilicity. This was indeed observed for the PGS containing fibers. These mats tend to absorb the water more or less rapidly by capillarity due to its hydrophilicity. After curing at $90^{\circ} \mathrm{C}$, the speed of water absorption is decreased while the mats become superhydrophobic, like pure PLA scaffolds after a curing step at $120^{\circ} \mathrm{C}$. This is due to the consumption of the hydrophilic chemical groups, and also to the roughness induced by the fibrous structure. ${ }^{34}$ This hydrophobicity of the PLA:PGS membranes is not conform to Yan et al.'s results, where a superhydrophilic behavior was found for such membranes cured 2 days at $120^{\circ} \mathrm{C}$ under vacuum. ${ }^{15}$ However, it is difficult to compare Yan's materials to the mats prepared in the present work, as PGS was prepared with other synthesis parameters, probably resulting in different crosslinking degree. PGS crosslinking has also a major influence on the mechanical properties of the scaffolds. As previously reported, the Young's modulus of the PGS increases with the annealing temperature ${ }^{35}$. Indeed, the higher temperature accelerates the reaction and leads to a higher crosslinking density of the PGS.

For the fibers containing PGS, as previous discussed, flowing of the pPGS occurring during annealing results in fixed contact points between fibers, thus forming a reinforced net, and scaffold with lower porosity. These two parameters further enhance the Young's modulus and UTS of the electrospun mats.

Finally, the curing step increases the mechanical strength of the scaffolds but decreases its hydrophilicity. Six different fibrous mats were then tested for their use in heart regeneration: pure PLA mats with a mean fiber diameter in the range of $600 \mathrm{~nm}$, cured at $120^{\circ} \mathrm{C}$ or uncured, hydrophobic with a WCA of $128^{\circ}$, PLA:PGS thin $_{\text {and PLA:PGS }}$ thick mats with mean fibers diameter of 600 and $1300 \mathrm{~nm}$ respectively, cured at $90^{\circ} \mathrm{C}$ with medium hydrophilicity and 
medium Young's modulus of $184 \pm 26$ and $55 \pm 25 \mathrm{MPa}$ respectively, and the same electrospun mats cured at $120^{\circ} \mathrm{C}$, hydrophobic and with higher Young's Modulus of $278 \pm 9.8$ and $216 \pm 48 \mathrm{MPa}$.

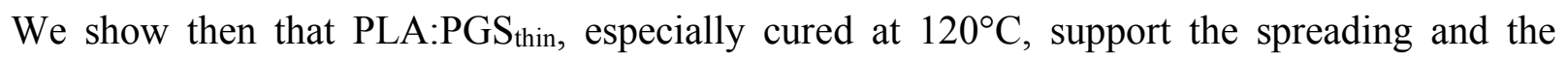
infiltration of the cardiomyocytes after 6 days of culture. This result is in accordance with the

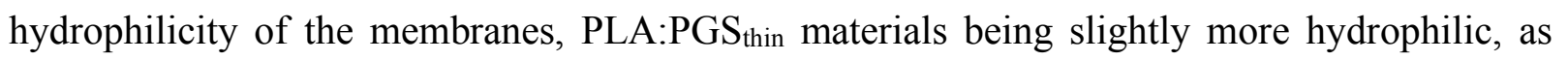
shown on Figure 4. This allows a better interaction with matrigel, which is confirmed by the absence of visible matrigel film between PLA:PGS fibers, whereas such film is visible at the surface of PLA fibers (see Figures 6A-B). Matrigel is a protein mixture of laminin, collagen IV, entactin, collagen and heparin sulfate proteoglycan and some growth factors, which has been shown to improve the cardiac markers and the properties of neonatal rat cardiomyocytes on a scaffold. ${ }^{36}$ Consequently, the improved matrigel coating of PLA:PGS $\mathrm{thin}_{\text {membranes due }}$ to their hydrophilicity allows a better material-cell interaction promoting an efficient cellularization and colonization by contrast to pure PLA membranes.

The curing condition at $90^{\circ} \mathrm{C}$ does not improve the cell spreading on the mats despite a higher hydrophilicity matching with matrigel-coated mats. This result can be due to a less complete crosslinking reaction, meaning more unreacted carboxylic acids. Yet, these acids are identified as responsible for PGS cytotoxicity. ${ }^{37}$ Surprisingly, PLA:PGS thick $_{\text {scaffolds allow less }}$ cardiomyocytes spreading, whereas chemical composition is similar to PLA:PGS thin $_{\text {mats. The }}$ slightly higher WCA measured for the thick fibers would not explain this difference, because we think that this increase is explained by the roughness of the materials rather than the hydrophilicity of the material in the fibers. Beside, tensile tests revealed a higher stiffness for PLA:PGS thin $_{\text {mats }}$ whereas lower substrate stiffness should be better for cardiac cells culture. ${ }^{38}$ Despite the fact that the moduli measured here correspond to the deformation of the whole fibrous mats, and not to the stiffness perceived by the cells, the crystallinity measurements tell us that the thin fibers themselves are certainly more rigid. The differences in the mechanical 
properties should thus not explain the different behavior of cells. The result should actually be also explained by thinner size of the fibers which enhance cardiomyocytes spreading.

The application of a scaffold in cardiac tissue engineering involves a biocompatibility including low immune response associated to increased vascularization to support the loss of tissue. Furthermore, cardiac remodeling after myocardial infarction is a dynamic process, but most of the geometric changes of left ventricle occur within the first weeks. Certainly, the integrity of the scaffold is necessary during this remodeling period, but after that, it should gradually degrade.

In this study, experiments show that pure PLA fibers have diffuse structure with cell infiltration. This phenomenon can be easily understood thanks to the SEM observation (Figure 2A). Indeed, fibers are visibly less attached together in comparison to PLA:PGS fibers, were some melted pPGS connect fibers together. The presence of mononuclear cells with the accumulation of multinucleated giant cells at the grafted area after 28 days indicate also a chronic immune response against the mats. By contrast, the inflammatory response is weaker for PLA:PGS thin cured at $120^{\circ} \mathrm{C}$ mats, despite a very low cell infiltration. Its better biocompatibility can again be explained by its higher hydrophilicity, parameter known to have a better tolerance to the organ host. ${ }^{39}$ In previous report, it has been noticed that the degradability rate of PGS were too fast for the cardiac remodeling process with complete absorption in 1 to 2 months. ${ }^{32}$ We demonstrate that, even with PGS as one of the component, the scaffold kept a good integrity during 28 days, indicating its suitability for cardiac tissue engineering.

The continuation of this study will consist of cellularized scaffold optimization for a therapeutic application. Although promising in vitro results with the cardiomyocytes on matrigel coated mats, matrigel based surface functionalization is not appropriate for clinical translation because of its origin derived from a mouse tumor ${ }^{40}$. In this context, complementary analyses was carried out with laminin (see Figure 6F) and the results have still confirmed that 
the PLA:PGS blend fibers have a high potential in cardiac tissue engineering. In this direction, more explorations will be necessary to determine the optimal cellularization of the scaffolds matching the contractile force as close to the explanted adult cardiac tissue (around 50 $\left.\mathrm{mM} / \mathrm{mm}^{2}\right)^{41}$ in order to evaluate the potential cardiac function recovery in diseased heart after transplantation.

\section{Conclusions}

In this work, potential scaffolds for cardiac tissue engineering were prepared by blend electrospinning of PLA:pPGS. A sufficient curing of the mats (2 days at $\left.120^{\circ} \mathrm{C}\right)$ leads to a low cytotoxicity of the scaffolds. It also induces the crystallization of the PLA and thus the stiffening of the material, but this allows a good resistance to sterilization by autoclave. The presence of PGS increases the hydrophilicity and contributes to a better functionalization by matrigel. PLA:PGS matrigel-coated scaffolds allow thus better cardiomyocytes spreading and penetration. Results are better for thin fibers $(600 \mathrm{~nm}$ in average diameter) than for thick fibers

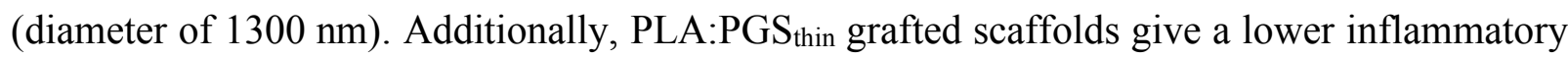
response associated with an increased vascularization than pure PLA scaffolds, pointing out that the first is the best candidate for cardiac tissue engineering. Finally, the ability of

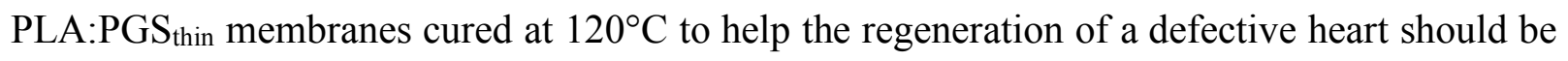
tested in future experiments.

\section{ASSOCIATED CONTENT}

\section{Supporting Information}

Chemical scheme and synthesis of pPGS. Complementary SEM and fluorescent pictures. SEC and DSC characterization. Mechanical results. Cardiomyocytes of scaffolds functionalized with laminin. 


\section{Corresponding Author}

*Prof. Guy Schlatter, guy.schlatter@unistra.fr

*Prof. Onnik Agbulut, onnik.agbulut@,sorbonne-universite.fr

\section{Notes}

The authors declare no competing financial interest and no conflict.

\section{Funding Sources}

This work was supported by funds from University of Strasbourg, Sorbonne University, the CNRS, the Agence Nationale de la Recherche (MimHeart project ANR-15-CE08-0010-02), the LabEx REVIVE (ANR-10-LABX-73), the Fondation de l'Avenir (grant number AP-RM-17032) and the Fédération Française de Cardiologie.

\section{Acknowledgements}

The authors thank the financial supports of University of Strasbourg, Sorbonne University, CNRS, the Agence Nationale de la Recherche (MimHeart project ANR-15-CE08-0010-02), the LabEx REVIVE (ANR-10-LABX-73), the Fondation de l'Avenir (grant number AP-RM-17032) and the Fédération Française de Cardiologie.

\section{References}

(1) Cannon, B. Cardiovascular Disease: Biochemistry to Behaviour. Nature 2013, 493, S2-S3. https://doi.org/10.1038/493S2a.

(2) Go, A. S.; Mozaffarian, D.; Roger, V. L.; Benjamin, E. J.; Berry, J. D.; Blaha, M. J.; Dai, S.; Ford, E. S.; Fox, C. S.; Franco, S.; et al. Heart Disease and Stroke Statistics--2014 
Update: A Report from the American Heart Association. Circulation 2014, 129 (3), e28-e292. https://doi.org/10.1161/01.cir.0000441139.02102.80.

(3) Boudriot, U.; Dersch, R.; Greiner, A.; Wendorff, J. H. Electrospinning Approaches Toward Scaffold Engineering-A Brief Overview. Artif. Organs 2006, 30 (10), 785792. https://doi.org/10.1111/j.1525-1594.2006.00301.x.

(4) Lannutti, J.; Reneker, D.; Ma, T.; Tomasko, D.; Farson, D. Electrospinning for Tissue Engineering Scaffolds. Mater. Sci. Eng. C 2007, 27 (3), 504-509.

https://doi.org/10.1016/j.msec.2006.05.019.

(5) Sell, S.; Barnes, C.; Smith, M.; McClure, M.; Madurantakam, P.; Grant, J.; McManus, M.; Bowlin, G. Extracellular Matrix Regenerated: Tissue Engineering via Electrospun Biomimetic Nanofibers. Polym. Int. 2007, 56 (11), 1349-1360. https://doi.org/10.1002/pi.2344.

(6) Agarwal, S.; Wendorff, J. H.; Greiner, A. Progress in the Field of Electrospinning for Tissue Engineering Applications. Adv. Mater. 2009, 21 (32-33), 3343-3351. https://doi.org/10.1002/adma.200803092.

(7) Kitsara, M.; Agbulut, O.; Kontziampasis, D.; Chen, Y.; Menasché, P. Fibers for Hearts: A Critical Review on Electrospinning for Cardiac Tissue Engineering. Acta Biomater. 2017, 48, 20-40. https://doi.org/10.1016/j.actbio.2016.11.014.

(8) Kitsara, M.; Joanne, P.; Boitard, S. E.; Ben Dhiab, I.; Poinard, B.; Menasché, P.; Gagnieu, C.; Forest, P.; Agbulut, O.; Chen, Y. Fabrication of Cardiac Patch by Using Electrospun Collagen Fibers. Microelectron. Eng. 2015, 144, 46-50. https://doi.org/10.1016/j.mee.2015.02.034.

(9) Joanne, P.; Kitsara, M.; Boitard, S.-E.; Naemetalla, H.; Vanneaux, V.; Pernot, M.; Larghero, J.; Forest, P.; Chen, Y.; Menasché, P.; et al. Nanofibrous Clinical-Grade Collagen Scaffolds Seeded with Human Cardiomyocytes Induces Cardiac Remodeling in Dilated Cardiomyopathy. Biomaterials 2016, 80, 157-168. https://doi.org/10.1016/j.biomaterials.2015.11.035.

(10) Cipitria, A.; Skelton, A.; R. Dargaville, T.; D. Dalton, P.; W. Hutmacher, D. Design, Fabrication and Characterization of PCL Electrospun Scaffolds-a Review. J. Mater. Chem. 2011, 21 (26), 9419-9453. https://doi.org/10.1039/C0JM04502K.

(11) Suwantong, O. Biomedical Applications of Electrospun Polycaprolactone Fiber Mats. Polym. Adv. Technol. 2016, 27 (10), 1264-1273. https://doi.org/10.1002/pat.3876.

(12) Jin, G.; He, R.; Sha, B.; Li, W.; Qing, H.; Teng, R.; Xu, F. Electrospun ThreeDimensional Aligned Nanofibrous Scaffolds for Tissue Engineering. Mater. Sci. Eng. C 2018, 92, 995-1005. https://doi.org/10.1016/j.msec.2018.06.065.

(13) Ishii, O.; Shin, M.; Sueda, T.; Vacanti, J. P. In Vitro Tissue Engineering of a Cardiac Graft Using a Degradable Scaffold with an Extracellular Matrix-like Topography. J. Thorac. Cardiovasc. Surg. 2005, 130 (5), 1358-1363. https://doi.org/10.1016/j.jtcvs.2005.05.048.

(14) Chen, Q.-Z.; Bismarck, A.; Hansen, U.; Junaid, S.; Tran, M. Q.; Harding, S. E.; Ali, N. N.; Boccaccini, A. R. Characterisation of a Soft Elastomer Poly(Glycerol Sebacate) Designed to Match the Mechanical Properties of Myocardial Tissue. Biomaterials 2008, 29 (1), 47-57. https://doi.org/10.1016/j.biomaterials.2007.09.010.

(15) Yan, Y.; Sencadas, V.; Jin, T.; Huang, X.; Chen, J.; Wei, D.; Jiang, Z. Tailoring the Wettability and Mechanical Properties of Electrospun Poly(l-Lactic Acid)Poly(Glycerol Sebacate) Core-Shell Membranes for Biomedical Applications. J. Colloid Interface Sci. 2017, 508, 87-94. https://doi.org/10.1016/j.jcis.2017.08.033.

(16) Chen, Q.-Z.; Ishii, H.; Thouas, G. A.; Lyon, A. R.; Wright, J. S.; Blaker, J. J.; Chrzanowski, W.; Boccaccini, A. R.; Ali, N. N.; Knowles, J. C.; et al. An Elastomeric Patch Derived 
from Poly(Glycerol Sebacate) for Delivery of Embryonic Stem Cells to the Heart. Biomaterials 2010, 31 (14), 3885-3893.

https://doi.org/10.1016/j.biomaterials.2010.01.108.

(17) Yi, F.; LaVan, D. A. Poly(Glycerol Sebacate) Nanofiber Scaffolds by Core/Shell Electrospinning. Macromol. Biosci. 2008, 8 (9), 803-806.

https://doi.org/10.1002/mabi.200800041.

(18) Tallawi, M.; Dippold, D.; Rai, R.; D’Atri, D.; Roether, J. A.; Schubert, D. W.; Rosellini, E.; Engel, F. B.; Boccaccini, A. R. Novel PGS/PCL Electrospun Fiber Mats with Patterned Topographical Features for Cardiac Patch Applications. Mater. Sci. Eng. C 2016, 69, 569-576. https://doi.org/10.1016/j.msec.2016.06.083.

(19) Jeffries, E. M.; Allen, R. A.; Gao, J.; Pesce, M.; Wang, Y. Highly Elastic and Suturable Electrospun Poly(Glycerol Sebacate) Fibrous Scaffolds. Acta Biomater. 2015, 18, 30-39. https://doi.org/10.1016/j.actbio.2015.02.005.

(20) Xu, B.; Li, Y.; Fang, X.; Thouas, G. A.; Cook, W. D.; Newgreen, D. F.; Chen, Q. Mechanically Tissue-like Elastomeric Polymers and Their Potential as a Vehicle to Deliver Functional Cardiomyocytes. J. Mech. Behav. Biomed. Mater. 2013, 28, 354365. https://doi.org/10.1016/j.jmbbm.2013.06.005.

(21) O’Brien, F. J. Biomaterials \& Scaffolds for Tissue Engineering. Mater. Today 2011, 14 (3), 88-95. https://doi.org/10.1016/S1369-7021(11)70058-X.

(22) Jaafar, I. H.; Ammar, M. M.; Jedlicka, S. S.; Pearson, R. A.; Coulter, J. P. Spectroscopic Evaluation, Thermal, and Thermomechanical Characterization of Poly(GlycerolSebacate) with Variations in Curing Temperatures and Durations. J. Mater. Sci. 2010, 45 (9), 2525-2529. https://doi.org/10.1007/s10853-010-4259-0.

(23) Inai, R.; Kotaki, M.; Ramakrishna, S. Deformation Behavior of Electrospun Poly(LLactide-Co-e-Caprolactone) Nonwoven Membranes under Uniaxial Tensile Loading. J. Polym. Sci. Part B Polym. Phys. 2005, 43 (22), 3205-3212. https://doi.org/10.1002/polb.20457.

(24) Morel, A.; Domaschke, S.; Urundolil Kumaran, V.; Alexeev, D.; Sadeghpour, A.; Ramakrishna, S. N.; Ferguson, S. J.; Rossi, R. M.; Mazza, E.; Ehret, A. E.; et al. Correlating Diameter, Mechanical and Structural Properties of Poly(l-Lactide) Fibres from Needleless Electrospinning. Acta Biomater. 2018, 81, 169-183. https://doi.org/10.1016/j.actbio.2018.09.055.

(25) Migliaresi, C.; Cohn, D.; Lollis, A. D.; Fambri, L. Dynamic Mechanical and Calorimetric Analysis of Compression-Molded PLLA of Different Molecular Weights: Effect of Thermal Treatments. J. Appl. Polym. Sci. 1991, 43 (1), 83-95. https://doi.org/10.1002/app.1991.070430109.

(26) Ribeiro, C.; Sencadas, V.; Costa, C. M.; Gómez Ribelles, J. L.; Lanceros-Méndez, S. Tailoring the Morphology and Crystallinity of Poly(L-Lactide Acid) Electrospun Membranes. Sci. Technol. Adv. Mater. 2011, 12 (1). https://doi.org/10.1088/14686996/12/1/11660947.

(27) Chen, Q.; Liang, S.; Thouas, G. A. Elastomeric Biomaterials for Tissue Engineering. Prog. Polym. Sci. 2013, 38 (3), 584-671. https://doi.org/10.1016/j.progpolymsci.2012.05.003.

(28) D’Sa, R. A.; Raj, J.; Dickinson, P. J.; McCabe, F.; Meenan, B. J. Human Fetal Osteoblast Response on Poly(Methyl Methacrylate)/Polystyrene Demixed Thin Film Blends: Surface Chemistry Vs Topography Effects. ACS Appl. Mater. Interfaces 2016, 8 (24), 14920-14931. https://doi.org/10.1021/acsami.5b08073.

(29) Kitsara, M.; Blanquer, A.; Murillo, G.; Humblot, V.; Vieira, S. D. B.; Nogués, C.; Ibáñez, E.; Esteve, J.; Barrios, L. Permanently Hydrophilic, Piezoelectric PVDF Nanofibrous 
Scaffolds Promoting Unaided Electromechanical Stimulation on Osteoblasts. Nanoscale 2019, 11 (18), 8906-8917. https://doi.org/10.1039/C8NR10384D.

(30) Kurusu, R. S.; Demarquette, N. R. Wetting of Hydrophilic Electrospun Mats Produced by Blending SEBS with PEO-PPO-PEO Copolymers of Different Molecular Weight. Langmuir 2016, 32 (7), 1846-1853.

https://doi.org/10.1021/acs.langmuir.5b04287.

(31) Tandon, V.; Zhang, B.; Radisic, M.; Murthy, S. K. Generation of Tissue Constructs for Cardiovascular Regenerative Medicine: From Cell Procurement to Scaffold Design. Biotechnol. Adv. 2013, 31 (5), 722-735. https://doi.org/10.1016/j.biotechadv.2012.08.006.

(32) Stuckey, D. J.; Ishii, H.; Chen, Q.-Z.; Boccaccini, A. R.; Hansen, U.; Carr, C. A.; Roether, J. A.; Jawad, H.; Tyler, D. J.; Ali, N. N.; et al. Magnetic Resonance Imaging Evaluation of Remodeling by Cardiac Elastomeric Tissue Scaffold Biomaterials in a Rat Model of Myocardial Infarction. Tissue Eng. Part A 2010, 16 (11), 3395-3402. https://doi.org/10.1089/ten.tea.2010.0213.

(33) Tsuji, H.; Ikada, Y. Properties and Morphologies of Poly(l-Lactide): 1. Annealing Condition Effects on Properties and Morphologies of Poly(l-Lactide). Polymer 1995, 36 (14), 2709-2716. https://doi.org/10.1016/0032-3861(95)93647-5.

(34) Szewczyk, P. K.; Ura, D. P.; Metwally, S.; Knapczyk-Korczak, J.; Gajek, M.; Marzec, M. M.; Bernasik, A.; Stachewicz, U. Roughness and Fiber Fraction Dominated Wetting of Electrospun Fiber-Based Porous Meshes. Polymers 2019, 11 (1), 34. https://doi.org/10.3390/polym11010034.

(35) Li, X.; Hong, A. T.-L.; Naskar, N.; Chung, H.-J. Criteria for Quick and Consistent Synthesis of Poly(Glycerol Sebacate) for Tailored Mechanical Properties.

Biomacromolecules 2015, 16 (5), 1525-1533. https://doi.org/10.1021/acs.biomac.5b00018.

(36) Park, H.; Radisic, M.; Lim, J. O.; Chang, B. H.; Vunjak-Novakovic, G. A Novel Composite Scaffold for Cardiac Tissue Engineering. In Vitro Cell. Dev. Biol. Anim. 2005, 41 (7), 188-196. https://doi.org/10.1290/0411071.1.

(37) Li, Y.; Cook, W. D.; Moorhoff, C.; Huang, W.-C.; Chen, Q.-Z. Synthesis, Characterization and Properties of Biocompatible Poly(Glycerol Sebacate) PrePolymer and Gel. Polym. Int. 2012, 62 (4), 534-547.

https://doi.org/10.1002/pi.4419.

(38) Bhana, B.; Iyer, R. K.; Chen, W. L. K.; Zhao, R.; Sider, K. L.; Likhitpanichkul, M.; Simmons, C. A.; Radisic, M. Influence of substrate stiffness on the phenotype of heart cells http://onlinelibrary.wiley.com/doi/abs/10.1002/bit.22647 (accessed Jun 26, 2019). https://doi.org/10.1002/bit.22647.

(39) Franz, S.; Rammelt, S.; Scharnweber, D.; Simon, J. C. Immune Responses to Implants - A Review of the Implications for the Design of Immunomodulatory Biomaterials. Biomaterials 2011, 32 (28), 6692-6709. https://doi.org/10.1016/j.biomaterials.2011.05.078.

(40) Segers Vincent F.M.; Lee Richard T.; Dimmeler Stefanie; Losordo Douglas. Biomaterials to Enhance Stem Cell Function in the Heart. Circ. Res. 2011, 109 (8), 910-922. https://doi.org/10.1161/CIRCRESAHA.111.249052.

(41) Hasenfuss G; Mulieri L A; Blanchard E M; Holubarsch C; Leavitt B J; Ittleman F; Alpert N R. Energetics of Isometric Force Development in Control and VolumeOverload Human Myocardium. Comparison with Animal Species. Circ. Res. 1991, 68 (3), 836-846. https://doi.org/10.1161/01.RES.68.3.836. 
Table of Contents Graphic

Design of functional electrospun scaffolds based on poly(glycerol sebacate) elastomer and poly(lactic acid) for cardiac tissue engineering

Florence Flaig, Hélène Ragot, Alexandre Simon, Gaëlle Revet, Maria Kitsara, Lisa Kitasato, Anne Hébraud, Onnik Agbulut, Guy Schlatter

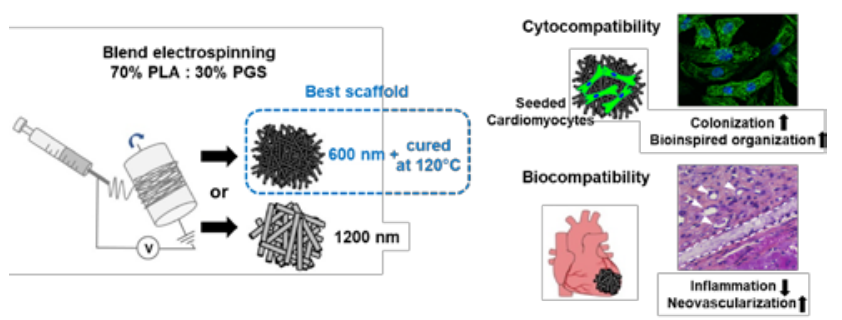

